\title{
IMA Genome - F13
}

\section{Draft genome sequences of Ambrosiella cleistominuta, Cercospora brassicicola, C. citrullina, Physcia stellaris, and Teratosphaeria pseudoeucalypti}

\author{
P. Markus Wilken ${ }^{1 *}$, Janneke Aylward ${ }^{1,2}$, Ramesh Chand ${ }^{3}$, Felix Grewe ${ }^{4}$, Frances A. Lane ${ }^{1}$, Shagun Sinha ${ }^{3,5 \dagger}$, \\ Claudio Ametrano ${ }^{4}$, Isabel Distefano ${ }^{4}$, Pradeep K. Divakar ${ }^{6}$, Tuan A. Duong ${ }^{1}$, Sabine Huhndorf ${ }^{4}$, \\ Ravindra N. Kharwar ${ }^{5}$, H. Thorsten Lumbsch ${ }^{4}$, Sudhir Navathe ${ }^{7 \dagger}$, Carlos A. Pérez ${ }^{8}$, Nazaret Ramírez-Berrutti ${ }^{8}$, \\ Rohit Sharma ${ }^{9}$, Yukun Sun ${ }^{4}$, Brenda D. Wingfield ${ }^{1}$ and Michael J. Wingfield ${ }^{1}$
}

\begin{abstract}
Draft genomes of the fungal species Ambrosiella cleistominuta, Cercospora brassicicola, C. citrullina, Physcia stellaris, and Teratosphaeria pseudoeucalypti are presented. Physcia stellaris is an important lichen forming fungus and Ambrosiella cleistominuta is an ambrosia beetle symbiont. Cercospora brassicicola and C. citrullina are agriculturally relevant plant pathogens that cause leaf-spots in brassicaceous vegetables and cucurbits respectively. Teratosphaeria pseudoeucalypti causes severe leaf blight and defoliation of Eucalyptus trees. These genomes provide a valuable resource for understanding the molecular processes in these economically important fungi.
\end{abstract}

KEYWORDS: Ambrosia beetle, Cercospora, Brassica rapa subsp. rapa, Foliose lichens, Lagenaria siceraria, Physcia, Teratosphaeria, Eucalyptus leaf pathogen

\section{IMA GENOME-F 13A}

Draft nuclear genome assembly for Ambrosiella cleistominuta, an ambrosia beetle symbiont Introduction

Fungi in the genus Ambrosiella (Microascales, Ceratocystidaceae) form an obligate, mutualistic symbiosis with ambrosia beetles from the tribe Xyleborini (Mayers et al. 2015). The fungi are dispersed by the ambrosia beetles through a specialised organ called the mycangium (Batra 1963). This sac-like structure is used by the beetle to carry the fungi in a budding yeast-like or arthrosporelike phase from tree to tree (Harrington et al. 2014). Once introduced into a new host tree, the fungus

\footnotetext{
* Correspondence: markus.wilken@fabi.up.ac.za

†'Shagun Sinha and Sudhir Navathe contributed equally to this work

'Department of Biochemistry, Genetics and Microbiology, Forestry and Agricultural Biotechnology Institute (FABI), University of Pretoria, Private Bag $\times 20$, Hatfield, Pretoria 0028, South Africa

Full list of author information is available at the end of the article
}

colonizes the wood and the galleries created by the beetle, producing special spores or modified hyphal endings that the insects consume as a food source (Batra 1963; Harrington 2005). Currently, ten species of Ambrosiella are formally recognized: $A$. beaveri, $A$. nakashimae, $A$. hartigii, A. batrae, A. xylebori, A. roeperi, A. grosmanniae (Mayers et al. 2015), A catenulata (Lin et al. 2017), A. cleistominuta (Mayers et al. 2017), and A. remansi (Mayers et al. 2019).

Ambrosiella cleistominuta was described from the mycangium of the ambrosia beetle Anisandrus maiche (Mayers et al. 2017). That beetle is native to Asia, but has recently become invasive in the USA, often infecting flood-stressed Cornus florida trees in Ohio (Ranger et al. 2015). Ambrosiella cleistominuta was the only species constantly isolated from the mycangia of these invasive beetles. Ascomata were subsequently identified in laboratory cultures of the fungus, as well as in artificially

(C) The Author(s). 2020 Open Access This article is licensed under a Creative Commons Attribution 4.0 International License, which permits use, sharing, adaptation, distribution and reproduction in any medium or format, as long as you give

appropriate credit to the original author(s) and the source, provide a link to the Creative Commons licence, and indicate if changes were made. The images or other third party material in this article are included in the article's Creative Commons licence, unless indicated otherwise in a credit line to the material. If material is not included in the article's Creative Commons licence and your intended use is not permitted by statutory regulation or exceeds the permitted use, you will need to obtain permission directly from the copyright holder. To view a copy of this licence, visit http://creativecommons.org/licenses/by/4.0/ 
infested stem segments of Cornus florida (Mayers et al. 2017). This was a surprising finding as ambrosia fungi are generally considered to be strictly asexual (Farrell et al. 2001; Harrington 2005).

Here we report a draft nuclear genome assembly for Ambrosiella cleistominuta. The complete genome sequence of $A$. xylebori is already publicly available (Vanderpool et al. 2017), and the addition of this genome opens the door for comparative genomic studies. Genome-based comparative studies have already provided a better understanding of the biology for many Ceratocystidaceae species (van der Nest et al. 2015; Simpson et al. 2018; Sayari et al. 2019; van der Nest et al. 2019), and the availability of another genome for this family will strengthen such studies in future.

\section{Sequenced strain}

USA: Ohio: Wayne County, near Barnard Rd., isol. from an Anisandrus maiche female caught in-flight, 8 Jul. 2015, C. Ranger (CBS 141682, BPI 910177 - dried culture).

\section{Nucleotide sequence accession number}

This Whole Genome Shotgun project for Ambrosiella cleistominuta isolate CBS 141682 has been deposited at DDBJ/ENA/GenBank under the accession JABFIG000000000. The version described in this paper is version JABFIG010000000.

\section{Materials and methods}

Ambrosiella cleistominuta isolate CBS 141682 was obtained from the Westerdijk Fungal Biodiversity Institute in Utrecht, The Netherlands (formerly the CBS-KNAW Fungal Biodiversty Centre) and grown on $2 \%$ malt extract agar (MEA: $2 \% \mathrm{w} / \mathrm{v}$, Biolab, South Africa) at $25^{\circ} \mathrm{C}$. A $14 \mathrm{~d}$ old culture was used for genomic DNA isolation which was sent to the Central Analytical Facility at the University of Stellenbosch (Stellenbosch, South Africa). The isolated DNA was used to prepare a $400 \mathrm{bp}$ singleread library that was sequenced on the Ion Torrent Ion S5 system (Thermo Fisher Scientific, Johannesburg, South Africa) with the Ion 530 Chip Kit. Additional genomic DNA was isolated from $14 \mathrm{~d}$ old cultures grown on a cellophane sheet on 2\% MEA using a DNeasy Plant Mini Kit (Qiagen, Germany). This DNA was sent to the Agricultural Research Council Biotechnology Platform (ARC-BTP; Pretoria, South Africa) where it was used to prepare a pair-end library with an insert size of $500 \mathrm{bp}$. The Illumina HiSeq 2500 instrument (Illumina, San Diego, CA) was used to generate $125 \mathrm{bp}$ length reads from both ends of the insert.

The IonTorrent reads obtained were used for readerror correction and assembly with SPAdes v. 3.14.0 using custom K-values $(21,33,43,55,67,77,87,99$,
101, 111, 121, 125), flagging the data as IonTorrent (Bankevich et al. 2012) and applying the "careful" option to reduce mismatches. The generated IonTorrent assembly scaffolds were then used as trusted contigs together with the Illumina data in a second assembly using SPAdes with default settings. The resulting assembly was assessed for completeness using the Benchmarking Universal Single Copy Orthologs tool (BUSCO v. 2.0.1) (Simão et al. 2015) and the Fungi_odb9 (2017-02-13) dataset. An estimation of the number of protein coding genes in the genome were made by the de novo prediction software AUGUSTUS using the Fusarium graminearum gene models (Stanke et al. 2006; Keller et al. 2011), while general genome statistics (genome length, GC content, N50, L50 and largest contig size) were calculated using QUAST v. 5.0.1 (Mikheenko et al. 2018).

The tef1- $\alpha$ gene region was extracted from the draft genome assembly and, together with previously published tef1- $\alpha$ sequences from $A$. catenulata (Lin et al. 2017), A. beaveri, A. nakashimae, A. hartigii, A. batrae, A. xylebori, A. roeperi, A. grosmanniae (Mayers et al. 2015), A. cleistominuta (Mayers et al. 2017) and A. remansi (Mayers et al. 2019), were used for phylogenetic analysis. The dataset consisting of these sequences were used to create a maximum likelihood phylogeny through the Phylogeny.fr online tool (Dereeper et al. 2008, 2010). The "one click" option was used that includes a MUSCLE alignment (Edgar 2004) and Gblocks curation step (Castresana 2000) that precedes phylogenetic analysis using PhyML (Guindon and Gascuel 2003). For branch support, an approximate likelihood ratio test was employed (Anisimova and Gascuel 2006).

\section{Results and discussion}

The draft genome sequence of A. cleistominuta (Fig. 1) presented here has a total length of 27,307,632 bp. This assembly was present in 1517 contigs, with the longest being $555,520 \mathrm{bp}$ and a total of 527 contigs longer than $1000 \mathrm{bp}$, and had a N50 value of $108,394 \mathrm{bp}$ and a L50 value of 73 . The genome had a GC content of $46.71 \%$ and an average coverage of $38 \mathrm{x}$, while AUGUSTUS predicted 6611 protein coding genes. BUSCO analysis reported a completeness score of $98.3 \%$. This was based on the analysis of 290 orthologs, with 285 present as complete and five copies completely absent.

The genome assembly of $A$. cleistominuta compared well to that of the previously published $A$. xylebori genome assembly (Vanderpool et al. 2017). The former genome has a higher estimated completeness $(98.3 \%$ vs 94.1\%) and a larger number of predicted genes (6611 vs 6503) compared to A. xylebori. However, the draft genome of $A$. cleistominuta is significantly more fragmented than that of $A$. xylebori ( 1517 vs 59 contigs), and this is further reflected in the larger N50 value of $A$. xylebori 


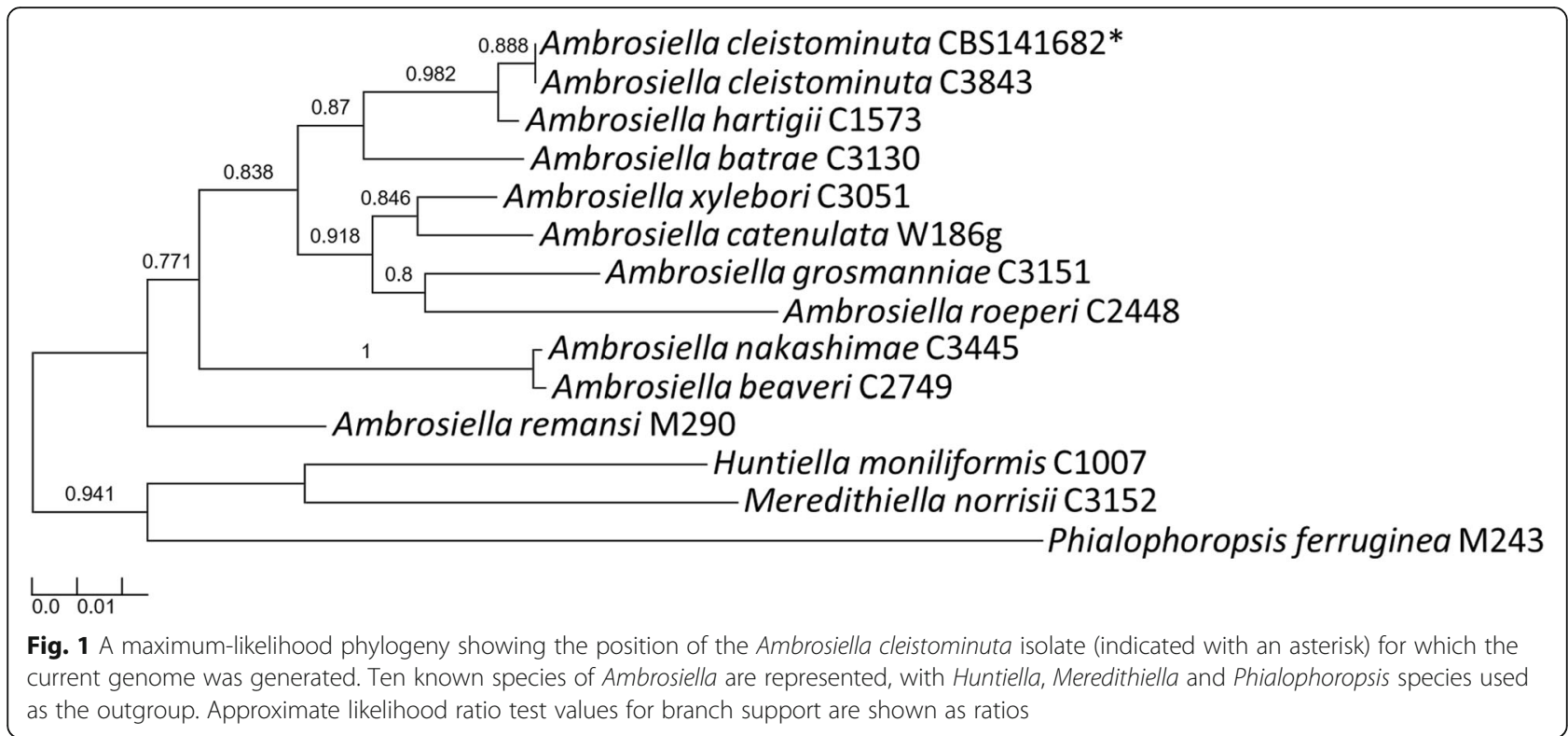

(108,394 bp vs $1,073,584$ bp). Combining a mate-pair library with the short-insert Illumina dataset during sequencing of the A. xylebori genome (Vanderpool et al. 2017) likely lowered fragmentation of the draft assembly, improving contiguity. Mate-pair data has effectively been used in the past to improve the assembly of mammalian (van Heesch et al. 2013), fungal (Wibberg et al. 2015) and plant (Belova et al. 2013) genomes. Similarly, the draft genome for $A$. cleistominuta presented here could be made more contiguous in future by using either mate-pair sequences or long-read sequences. Decreasing the fragmentation for the genome will make it more useful for studies such as whole-genome comparisons.

As A. cleistominuta is the first Ambrosiella species for which sexual reproduction was documented (Farrell et al. 2001; Harrington 2005; Mayers et al. 2017), the genome assembly reported here will be crucial to understanding the role of the sexual cycle in the biology of this species. Although sexual reproduction has not been observed in the other Ambrosiella species, there is growing evidence that asexual species may exhibit cryptic sexuality (Kück and Pöggeler 2009; Dyer and O'Gorman 2012; Ene and Bennett 2014). The genome assembly reported here will not only be useful to studying the matingtype genes of A. cleistominuta, but also of other Ambrosiella species. Additionally, the availability of a second Ambrosiella genome will support efforts to develop molecular tools for population genetic analyses that can be used to evaluate the population level effects of sexual reproduction (Paoletti et al. 2005).

Authors: Frances A. Lane ${ }^{*}$, Brenda D. Wingfield, and P. Markus Wilken

*Contact: Frances.Lane@fabi.up.ac.za

\section{IMA GENOME-F 13B}

Draft genome sequence of Cercospora brassicicola, causing White Leaf Spot on Brassica species Introduction

Cercospora white leaf spot on Brassica species is caused by Cercospora brassicicola. The genus Cercospora is one of the largest genera of Mycosphaerellaceae in Capnodiales (Groenewald et al. 2013). The conidiophores are pale olivaceous to medium brown, rarely branched, multiseptate, 0-7 abruptly geniculate with large spore scar at the sub-truncate tip and are of $3.5-7 \times 25-500 \mu \mathrm{m}$ in size whereas conidia are hyaline, acicular, curved or undulate, indistinctly multiseptate, truncate base, acute tip and of $2-5 \times 25-200 \mu \mathrm{m}$ in size (Fig. 2 C-D) (Chupp 1954). The hosts affected by this pathogen include Brassica chinensis, B. oleracea, B. pekinensis, B. rapa, $B$. juncea, B. nigra, B. napobrassicae (syn. B. campestris), $B$. integrifolia, B. napus, and other Brassica spp. (Chupp 1954; Hsieh and Goh 1990; Kamal 2010). The disease is widely spread in all tropical and subtropical countries. White leaf spots are circular to angular with a white center, and brown raised border (Fig. 2 A-B) (Chupp 1954). Leaf-spots cause discoloration and decay of petioles and blades, reducing product quality and value. Fields with such infected foliage are either sold on a discount rate or get rejected by the processors (Kahn et al. 2005). According to the U.S. Department of Agriculture standards for mustard and turnip, leaves with more than $10 \%$ of the surface area discolored are unsalable (Langston Jr et al. 2005).

Out of 935 species of Cercospora reported from India by Kamal (2010), only 1 published genome of C. canescens (Chand et al. 2015) exists. During a review of a yet unpublished monograph on the 


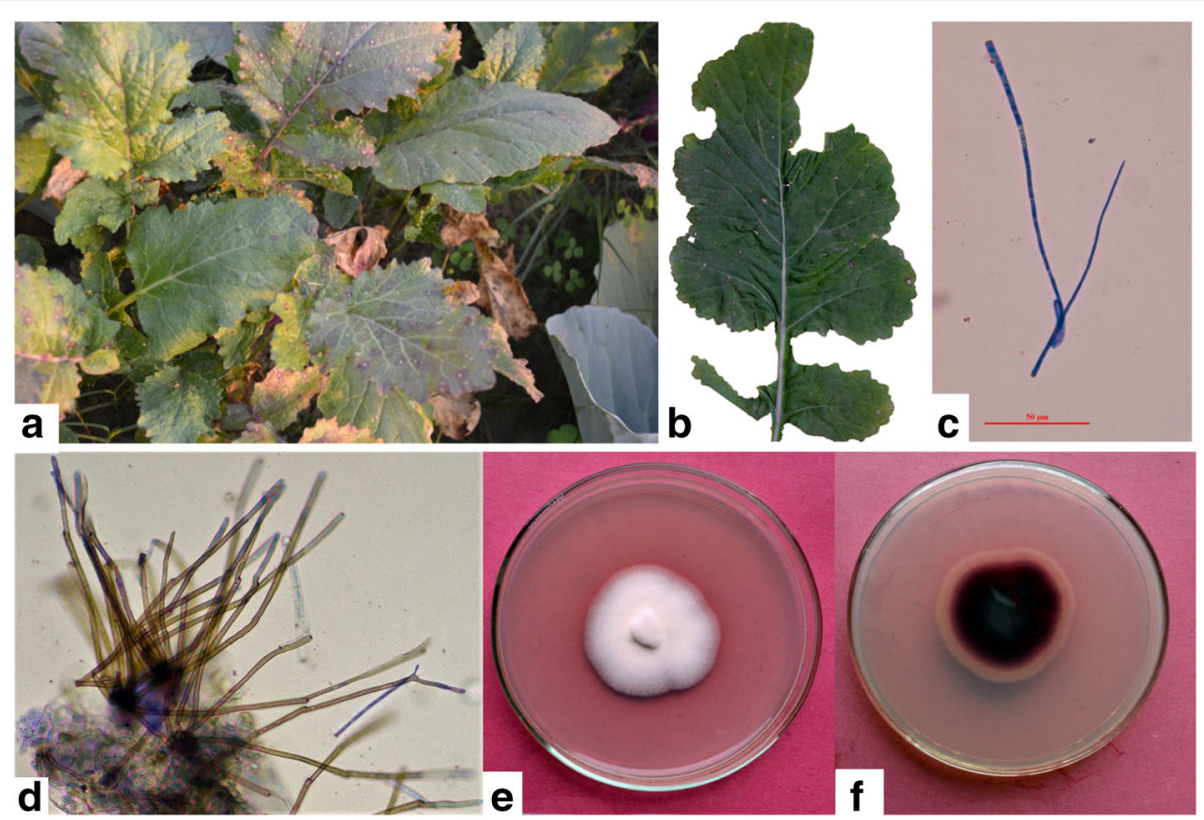

Fig. 2 Cercospora brassicicola (NFCCI 4678) on Brassica rapa subsp. rapa a-f, a-b. Symptoms on leaf c. Conidia d. Conidiophores e. Pigmented colony on potato dextrose agar (PDA) medium $\mathbf{f}$. Inverted pigmented colony. Bars: $\mathbf{c}$ and $\mathbf{d}=50 \mu \mathrm{m}$

cercosporoid fungi of India, it was found that there is little barcode information available from India. The additional genomic data can aid in better insights into host-pathogen interaction and disease management strategies.

\section{Sequenced strain}

India: Varanasi, Banaras Hindu University Agricultural Farm, isolated from infected leaf samples of Brassica rapa subsp. rapa, Feb. 2018, $R$. Chand E S. Sinha (Cer 68-18; NFCCI 4678).

\section{Nucleotide sequence accession numbers}

The genome sequence of Cercospora brassicicola (NFCCI 4678) has been deposited in the DDBJ/ENA/ GenBank databases under the accession number JAASLH000000000; Bio project PRJNA613165; Biosample SAMN14395395. The version described in this paper is version JAASLH010000000. The raw Illumina HiSeq sequence reads are deposited in NCBI-Sequence Read Archives (SRA) under accession SRX7967433. The genome annotation and data on predicted genes have been deposited in Mendeley data with doi number https://doi.org/10.17632/ gsdsb9m5w4.1.

\section{Materials and methods}

Isolation and DNA extraction A monoconidial isolate from infected leaves was grown in $40 \mathrm{ml}$ potato dextrose broth (20\% potato dextrose broth w/v) and incubated for
$7 \mathrm{~d}$ at $25 \pm 1{ }^{\circ} \mathrm{C}$. The fungal material was harvested aseptically after $7 \mathrm{~d}$ and genomic DNA was extracted using modified cetyltrimethylammonium bromide (CTAB) extraction protocol (Murray and Thompson 1980). Eppendorf BioPhotometer ${ }^{\circ} 30$ was used for the quantification of DNA.

PCR amplification and sequencing Sequencing of the internal transcribed spacer region (ITS), 28S rRNA gene (large subunit-LSU) and 18S rRNA gene (small subunitSSU) was accomplished by amplification using PCR Thermocycler (Eppendorf MasterCycler 5333) to confirm the identification of the fungal isolate. Primers used for amplification of different regions are as follows: ITS1 and ITS 4 for ITS1-5.8S-ITS2 region (White et al. 1990), LROR and LR7 for LSU region and NS1 and NS5 were used for SSU (https://sites.duke.edu/vilgalyslab/rdna primers_for_fungi). Amplification was performed using standard PCR conditions. The PCR products were checked on $1.5 \%$ agarose gel. The sequencing was outsourced at AgriGenome Labs (Kochi, India).

Phylogenetic analysis The seqs thus generated have been submitted at the National Centre for Biotechnology Information (NCBI). The sequences were checked and edited manually using Chromas Pro software (Technelysium). An NCBI BLASTn search for ITS sequence similarity was done with the type database of NCBI (Altschul et al. 1990). Based on the closest similarity of the BLASTn search, the ITS region sequences of ex-type and authentic strains, sequences from Groenewald et al. 
(2013), and Nguanhom et al. (2015) were retrieved from GenBank. Alignment of sequences was done using Clustal W of Molecular Evolutionary Genetics Analysis (MEGA) software v 7.0 (Kumar et al. 2016). Gaps and missing data were deleted during the sequence alignment. Phylogenetic tree construction using ITS region sequences was done by the Neighbour-Joining method (Fig. 3) (Saitou and Nei 1978). Confidence values for individual branches were determined by bootstrap analyses of 1000 replicates. Bootstrap values below 50\% were not considered.

Genome assembly and annotation The library was sequenced with Illumina using a combination of short insert paired-end $(2 \times 100 \mathrm{bp})$ and long insert mate-pair (2x250 bp) HiSeq 2500 platform. Initial quality control of the raw sequence reads was performed using FastQC (Andrews 2010). Remnant adapters and low-quality reads with average quality score less than 30 were filtered out in any of the paired end reads using AdapterRemovalV2 v 2.3.1 (Schubert et al. 2016). Finally, unique reads removing duplicated short reads were fetched using FastUniq v 1.1 (Xu et al. 2012). De novo assembly was performed using MaSuRCA v 2.3.2 (Zimin et al. 2013) using the 25, 33, 55, 77, 99, and $127 \mathrm{k}$-mers. All contigs below $500 \mathrm{bp}$ were discarded. Quality assessment of complete assembly statistics was performed in QUAST v 4.6 (Gurevich et al. 2013). Genome completeness was obtained using BUSCO v 2.0 (Simão et al. 2015). Genes were predicted with AUGUSTUS from the assembled contigs (Stanke and Morgenstern 2005). The predicted gene functions were compared with the UniProt (www.uniprot.org) and NCBI (www.ncbi.nlm.nih. gov) database using the BLASTx v 2.6.0 program with Evalue cut-off of $10^{-3}$. The best BLASTx hit based on query coverage, identity, similarity score and description of each gene was filtered out. The top BLASTX hit of each gene was studied and the organism name was extracted. The predicted genes were annotated against UniProt for gene ontology in terms of molecular functions, cellular components, and biological Processes.

\section{Results and discussion}

The assembled draft genome of $C$. brassicicola was estimated to be $38.34 \mathrm{Mb}$ corresponding to 3078 contigs larger than $500 \mathrm{bp}$ with an N50 value of $17,086 \mathrm{bp}$ and an average GC content of $52.84 \%$. Genome completeness analysis (BUSCO) suggests that the assembly covers 96.8\% (281/290) (C:281 [S:266, D:157], F:6, M:3, n:290) of the organism's gene content including 266 complete and single-copy ortholog. AUGUSTUS predicted a total of "11,797" genes in the assembly. The number of predicted genes with significant BLASTx matched with the UniProt database was "10,502" (89.02\%). The gene ontology in terms of molecular functions (1027 terms), cellular component (347 terms), and biological process (951 terms) were mapped.

There are very limited whole-genome sequence resources available in the genus Cercospora. Those that are available include $C$. canescens $(\sim 34 \mathrm{Mb}$; Chand et al.

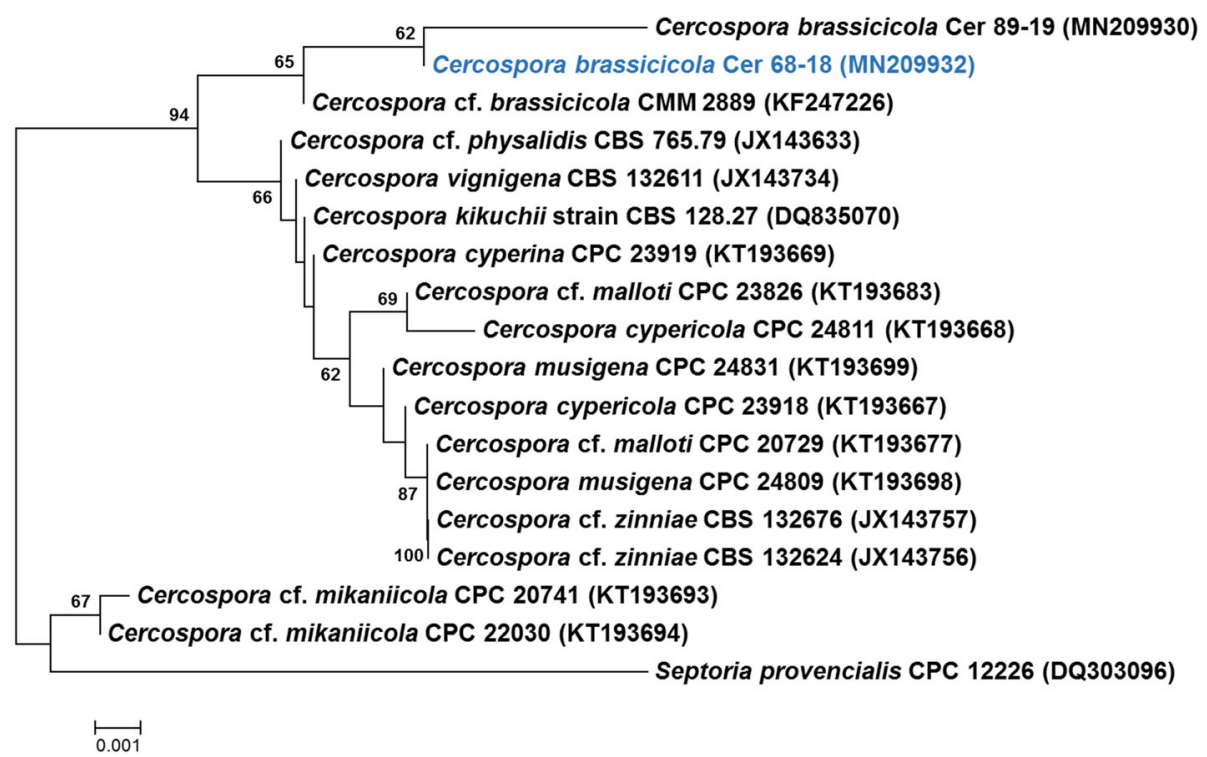

Fig. 3 Neighbor-Joining (NJ) tree of the nrlTS of Cercospora brassicicola. Sequence alignments were produced using Clustal W of Molecular Evolutionary Genetics Analysis (MEGA) software v 7.0 (Kumar et al. 2016). Bootstrap values below 50\% were not considered. The tree was rooted to Septoria provencialis. The percentage of replicate trees in which the associated taxa clustered together in the bootstrap test (1000 replicates) is shown next to the branches 
2015), C. arachidicola ( $33 \mathrm{Mb}$; Orner et al. 2015), C. cf. sigesbeckiae ( $35 \mathrm{Mb}$; Albu et al. 2017), C. zeina ( 37 Mb; Wingfield et al. 2017), C. sojina ( $30 \mathrm{Mb}$; Zeng et al. 2017), C. beticola ( 37 Mb; Wingfield et al. 2018a, b), and C. kikuchii ( 33 Mb; Sautua et al. 2019).

The genome resource of the C. brassicicola reported here is the first from Brassica rapa subsp. rapa. This will help in reducing the knowledge gap, which will help in the identification of loci associated with the virulence of the pathogen and in identifying the genetic variants and diagnostic tools.

Authors: Ramesh Chand", Shagun Sinha, Sudhir Navathe", Ravindra N. Kharwar, and Rohit Sharma

"Contact: sudhir.agro123@gmail.com,rc_vns@yahoo. co.in

\section{IMA GENOME-F 13C}

Draft genome sequence of Cercospora citrullina, causing Leaf Spot on cucurbits

\section{Introduction}

Cercospora leaf spot on cucurbits is caused by Cercospora citrullina. The disease is widespread in tropical and subtropical countries especially in the rainy season when high moisture levels and warm temperatures prevail. Leaf spots on cucurbits are circular to irregular, 0.5-7 $\mathrm{mm}$ diam, pale brown or tan to white, sometimes ashlike in appearance usually with a dark brown to black margin surrounded by yellow halo (Fig. 4a) (Chupp
1954). The centre of the spot eventually becomes transparent and brittle. The disease may cause leaf fall (Little 1987). The disease can also reduce fruit size and quality, but economic losses are rarely severe.

Genus Cercospora is one of the largest genera of the family Mycosphaerellaceae in Capnodiales (Groenewald et al. 2013). Cercospora citrullina is characterized by presence of conidiophores which are single or in spreading fascicles of $2-30$, mostly $2-5$, pale to very pale brown, uniform in width or mildly attenuated toward the distal end, occasionally swollen at some point, straight to slightly bent or curved, geniculations varying from none to numerous, multiseptate, not branched, fairly large spore scar at the sub-truncate tip and $4-5.5 \times 50-300 \mu \mathrm{m}$, rarely $6.5 \times 500 \mu \mathrm{m}$ in size. Conidia are hyaline, acicular, almost never obclavate, straight to strongly curved, indistinctly multiseptate, base truncate, tip acute, $2-4 \times 50-220 \mu \mathrm{m}$, or even as large as $5.5 \times 450 \mu \mathrm{m}$ in size (Fig. 4d-e) (Chupp 1954). Most of the cucurbitaceous hosts are infected by this pathogen; these include Benincasa, Bryonia, Citrullus vulgaris, Coccinia, Cucumis melo, C. sativus, Cucurbita foetidissima, C. maxima, C. pepo, Lagenaria leucantha, L. siceraria, Luffa cylindrica, Melothria, Momordica charantia, M. cochinchinensis, M. cordifolia, M. foetida, Sechium edule, Sicana odorifera, Telfairia, Trichosanthes anguina, and T. japonica (Chupp 1954; Little 1987; Hsieh and Goh 1990; Kamal 2010). The Cercospora species on cucurbits

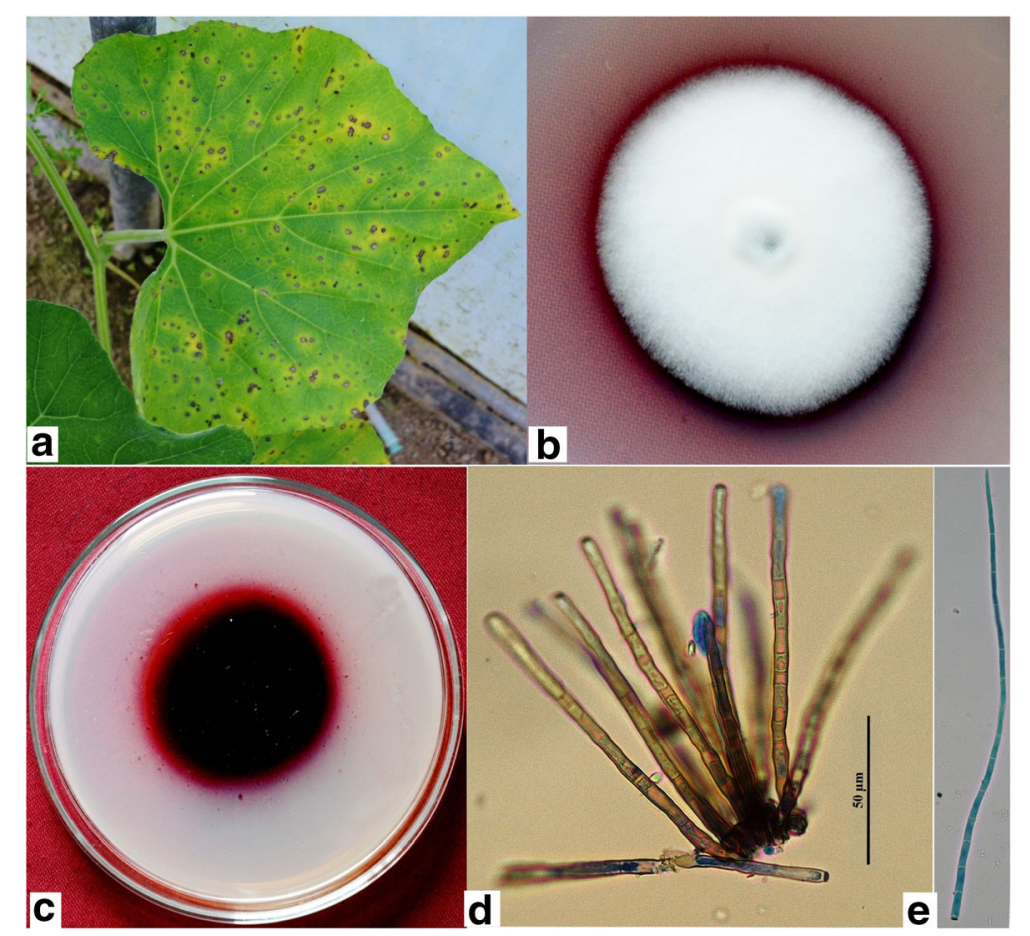

Fig. 4 Cercospora citrullina (NFCCI 3835) on Lagenaria siceraria. a. Symptoms on leaf b. Colony on potato dextrose agar c. Inverted pigmented colony d. Conidiophore e. Conidia 
invade to such an extent that it is impossible without careful cross inoculations to give host limits and synonymy. There is a lack of morphological differences to separate the morphs of this pathogen on the various hosts (Chupp 1954).

\section{Sequenced strain}

India: Varanasi, Mathurapur, isolated from infected leaf samples of Lagenaria siceraria, Oct. 2009, R. Chand (Cerl 37-09; NFCCI 3835).

\section{Nucleotide sequence accession numbers}

The genome sequence of Cercospora citrullina (NFCCI 3835) has been deposited in the DDBJ/ENA/GenBank databases under accession number JAASFF000000000; Bio-project PRJNA613165; Bio-sample SAMN14395396. The version described in this paper is version JAASFF010000000. The raw Illumina HiSeq sequence reads are deposited in the NCBI-Sequence Read Archives (SRA) under accession SRX7980601. The genome annotation and data on predicted genes have been deposited in Mendeley data with doi number https://doi. org/10.17632/hjnwp64z68.1.

\section{Materials and methods}

Isolation and identification Cercospora citrullina (NFCCI 3835) was isolated aseptically on potato dextrose agar medium (PDA) from infected leaves of Lagenaria siceraria. The culture was identified and deposited in NFCCI (National Fungal Culture Collection of India, Agharkar Research Institute, Pune, India).

DNA extraction and amplification The monoconidial isolate was grown in $40 \mathrm{ml}$ potato dextrose broth $(20 \%$ potato dextrose broth $\mathrm{w} / \mathrm{v}$ ) and incubated for $7 \mathrm{~d}$ at $25 \pm 1{ }^{\circ} \mathrm{C}$. Fungal material was harvested aseptically after $7 \mathrm{~d}$ and genomic DNA was extracted using a modified cetyltrimethylammonium bromide (CTAB) extraction protocol (Murray and Thompson 1980). Eppendorf BioPhotometer ${ }^{\circ} 30$ was used for the quantification of DNA. To ascertain authentic identification of the fungal isolate, sequencing of the internal transcribed spacer region (ITS), 28S rRNA gene (large subunit-LSU), and $18 \mathrm{~S}$ rRNA gene (small subunit- SSU) was accomplished by amplification using PCR thermocycler (Eppendorf 5333 MasterCycler Thermal Cycler). Primers used for amplification of different regions are as follows: ITS1 and ITS 4 for ITS1-5.8S-ITS2 region (White et al. 1990), LROR, and LR7 for LSU region and NS1 and NS5 were used for SSU (https://sites.duke.edu/vilgalyslab/rdna_primers_for_fungi). Amplification was performed using standard PCR conditions. The PCR products were checked on 1.5\% agarose gel. The sequencing was outsourced at AgriGenome Labs (Kochi, India).

Phylogenetic analysis The sequences thus generated have been submitted to the National Centre for Biotechnology Information (NCBI). The sequences were checked and edited manually using Chromas Pro software (Technelysium). NCBI BLASTn search for ITS sequence similarity was done with the type database of NCBI (Altschul et al. 1990). Based on the closest similarity of the BLASTn search, the ITS region sequences of ex-type and authentic strains, sequences from Groenewald et al. (2013), and Nguanhom et al. (2015) were retrieved from GenBank. The alignment of sequences was done using MAFFT v 7.0 (Katoh and Standley 2013). The phylogenetic analysis was conducted in MEGA v 7.0 (Kumar et al. 2016). Gaps and missing data were deleted during the sequence alignment. Phylogenetic tree construction using ITS region sequences was done by the Neighbour-Joining method (Fig. 5) (Saitou and Nei 1978). Confidence values for individual branches were determined by bootstrap analyses of 1000 replicates. Bootstrap values below $50 \%$ were not considered.

Genome sequencing, assembly, and annotation The library was sequenced on Illumina HiSeq 2500 platform with a combination of short insert paired-end $(2 \times 100 \mathrm{bp})$ and long insert mate-pair $(2 \times 250 \mathrm{bp})$. Initial quality control of the raw sequence reads was performed using FastQC (Andrews 2010). Remnant adapters and low-quality read with an average quality score of less than 30 in any of the paired-end reads were filtered out using AdapterRemovalV2 v 2.3.1 (Schubert et al. 2016). Finally, unique reads were obtained by removing duplicated short reads using FastUniq v 1.1 (Xu et al. 2012). De novo assembly was performed using Velvet v 1.2.10 (Zerbino and Birney 2008) optimized for k-mer values 31 to 95 . All contigs below $500 \mathrm{bp}$ were discarded. Quality assessment of complete assembly statistics was performed in QUAST v 4.6 (Gurevich et al. 2013). Genome completeness was obtained using BUSCO v 2.0 (Simão et al. 2015). Genes were predicted with AUGUSTUS from the assembled contigs (Stanke and Morgenstern 2005). The predicted gene functions were compared with UniProt (www.uniprot.org) and the NCBI database using the BLASTX $\mathrm{v} 2.6 .0$ program (www.ncbi.nlm.nih.gov) with an E-value cut-off of $10^{-3}$. The best BLASTX hit based on query coverage, identity, similarity score, and description of each gene was filtered out. The top BLASTX hit of each gene was studied and the organism name was extracted. The predicted genes were annotated against UniProt and NCBI database for gene ontology in terms of molecular functions, cellular components, and biological processes. 


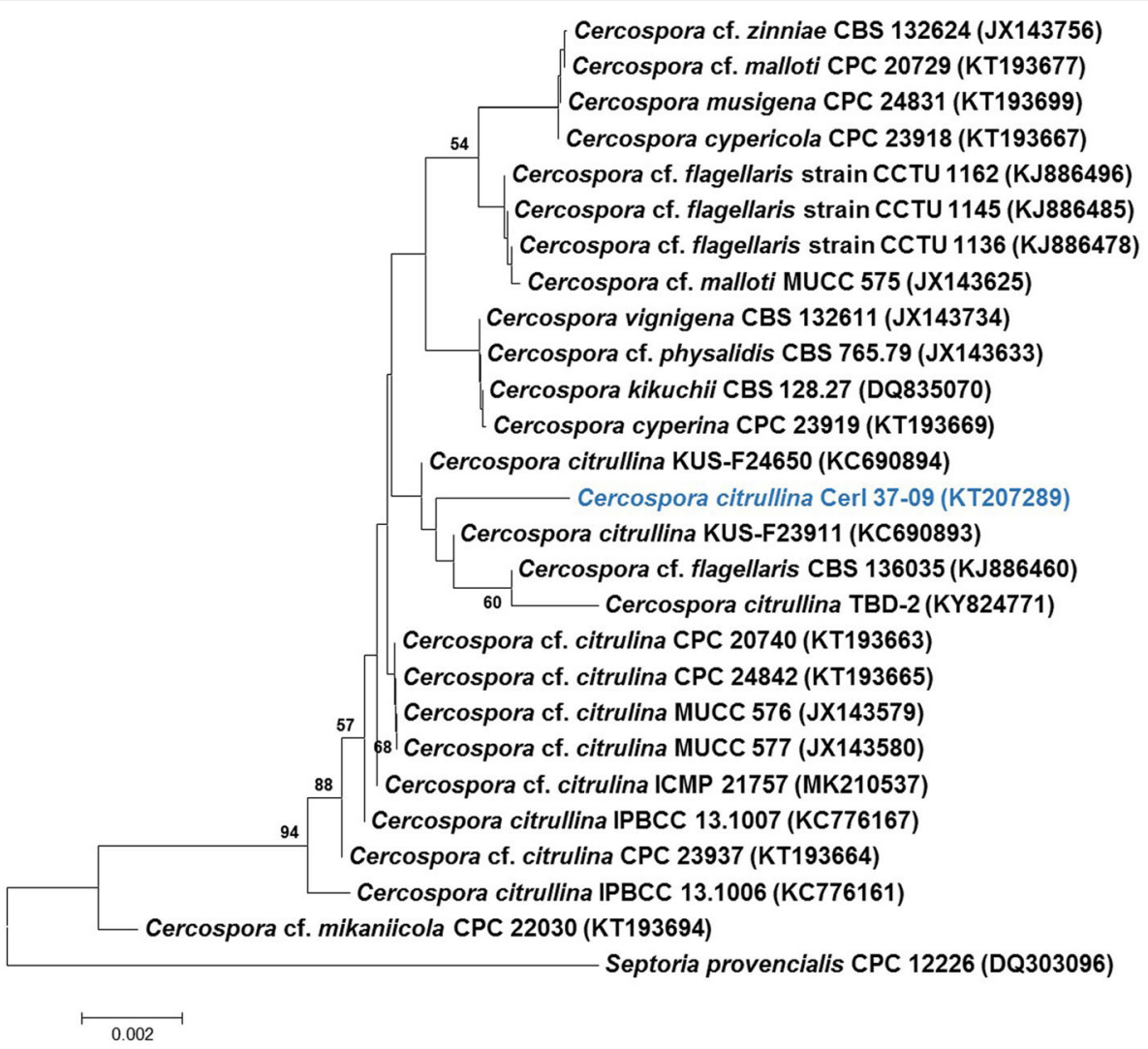

Fig. 5 Neighbour-Joining (NJ) tree of the nrlTS to identify the sequenced Cercospora citrullina. Sequence alignments were produced using MAFFT v 7 (Katoh and Standley 2013) anf further rendered in MEGA7. Bootstrap values below 50\% were not considered. The tree was rooted to Septoria provencialis. The percentage of replicate trees in which the associated taxa clustered together in the bootstrap test (1000 replicates) is shown next to the branches

\section{Results and discussion}

The genome resource of the Cercospora citrullina reported here is the first from Lagenaria siceraria. The paired-end and mate-pair sequencing generated approximately $370.23-426.16 \mathrm{Mb}$ raw reads. The assembled draft genome was estimated to be $45.30 \mathrm{Mb}$ corresponding to 358 contigs larger than $500 \mathrm{bp}$ with an N50 value of $637,436 \mathrm{bp}$, and an average GC content of $52.81 \%$. The largest contig was of $1,464,843 \mathrm{bp}$. Genome completeness analysis (BUSCO) suggests that the assembly covers $97.9 \%$ (284/290) (C: 284 [S: 283, D: 1], F: 3, M: 3, n: 290) of the organism's gene content that includes 283 complete and single-copy orthologs. AUGUSTUS predicted a total of "9917" genes in the assembly. The number of predicted genes with significant BLASTX matched with the UniProt database was "8856" (89.30\%). The gene ontology in terms of molecular functions (1015 terms), cellular component (336 terms), and biological process (958 terms) were mapped. The estimated genome size of $C$. citrullina ( $\sim 45 \mathrm{Mb})$ is comparable to that of other Cercospora species including, C. canescens
( 34 Mb; Chand et al. 2015), C. arachidicola ( 33 Mb; Orner et al. 2015), C. cf. sigesbeckiae ( $35 \mathrm{Mb}$; Albu et al. 2017), C. zeina ( $37 \mathrm{Mb}$; Wingfield et al. 2017), C. sojina ( $\sim 30 \mathrm{Mb}$; Zeng et al. 2017), C. beticola ( 37 Mb; Wingfield et al. 2018a, b) and C. kikuchii ( 33 Mb; Sautua et al. 2019). As per Wijayawardene et al. (2017), there are 3000 described species and 700 accepted species of Cercospora. However, there are only 18 genome assemblies available until now in global genomic databases (https://www.ncbi. nlm.nih.gov/datasets/genomes/?txid=29002). Therefore, there is a need to fill this knowledge gap with additional genomic data, which can be utilized in the understanding of host-pathogen interaction, loci associated with virulence and disease management strategies. Also, due to the absence of morphological differences in the morphs of $C$. citrullina on the various hosts, it is necessary to have genomic information that can be integrated with morphology to understand host limits and synonymy.

Authors: Shagun Sinha, Ramesh Chand", Sudhir Navathe", Ravindra N. Kharwar, and Rohit Sharma

"Contact: rc_vns@yahoo.co.in, sudhir.agro123@gmail.com 


\section{IMA GENOME-F 13D}

\section{Draft genome sequence of Physcia stellaris (Physciaceae) Introduction}

Physcia is one of 19 genera within the lichen-forming fungal family Physciaceae (Ascomycota, Caliciales) (Lücking et al. 2017). About 80 species of foliose lichens are recognized in Physcia (Lücking et al. 2017) and these occur in various habitats, including those rich in nitrogen (Janssen et al. 2007; Boltersdorf and Werner 2014).

In regions with nitrogen pollution, such as cities and regions impacted by agricultural activities, nitrophytic Physcia species have been known to outcompete native lichen asemblages (Conti and Cecchetti 2001; Van Herk et al. 2003; Jovan et al. 2012). Therefore, Physcia lichens have been used in surveys as bioindicator species. For example, they were used to monitor air health quality in Central Argentina (Estrabou et al. 2011), northeast Italy (Nimis et al. 1991), West Java (Rindita et al. 2015), and South-Eastern Serbia (Stamenković et al. 2010). Moreover, bioindicator lichens can also be used for a more direct estimate of pollution by measuring the pollutants (e.g. metals, metalloids, persistent organic pollutants, radioactive substances, and pesticides) that accumulate in the thallus. These pollutants have potential adverse impacts on human health and the environment. Hence, Physcia species have been used to develop lichen elemental bioindicators as part of a national monitoring program for air health quality (Will-Wolf et al. 2017).

We sequenced the first draft genome of the nitrogentolerant lichenized fungus Physcia stellaris. We collected the specimen for culturing of the mycobiont in Chicago, IL, which is the third largest city of the US and ranked the 16th most air polluted US city in the 2020 "State of the Air" report by the American Lung Association. Physcia stellaris is a common species in the midwestern US (Hyerczyk 2005) and characterized by a pale grey thallus with abundant dark brown to black apothecia on the upper surface (Moberg 2002). The species was considered to be cosmopolitan but molecular data show that Australian populations are unrelated and represent a distinct taxon, which is currently accepted as P. austrostellaris (Elix et al. 2009). Hence the species delimitation requires further studies, but the species has been confirmed with molecular data to be present in eastern North America and Europe. In addition to the species delimitation efforts of Elix et al. (2009), other previous phylogenetic studies including Physcia sequences have been performed to better understand the taxonomy of this group (Lohtander et al. 2000, 2009; Simon et al. 2005; Miadlikowska et al. 2014); however, no full genome in this particular lichen family has peviously been sequenced.

Our presented genome sequence of $P$. stellaris will serve as a reference for future phylogenetic and molecular biodiversity studies of the genus Physcia, which will help to determine population sizes, species ranges, and habitats. Understanding Physcia habitats and distributions will in turn allow researchers to better utilize the genus as a bioindicator of air polluted regions. As a bioindicator for air pollution, the genome sequence of $P$. stellaris may also help to reveal underlying genomic factors that better adapt these lichens to urban environments with high air pollution compared to other lichens.

\section{Sequenced strain}

USA: Illinois: Chicago, $41^{\circ} 52.00^{\prime} \mathrm{N}, 87^{\circ} 37.02^{\prime} \mathrm{W}$, isolated from thallus on a wooden park bench close to the North entrance of the Field Museum, 7 Aug. 2017, S.M. Huhndorf (C03752214F - specimen: \#10-5).

\section{Nucleotide sequence accession number}

The draft whole-genome sequence of the lichenized fungus Physcia stellaris (culture collection number \#10-5) has been deposited at DDBJ/EMBL/Genbank under the accession number JABSSW000000000. The version described in this paper is version JABSSW010000000.

\section{Materials and methods}

The Physcia stellaris specimen was identified by T.J. Widhelm on 18 Feb. 2020 and is retained in the collections of the Field Museum. Axenic cultures were produced from ascospores and grown on malt-yeast extract agar until the individual cultures reached sufficient sizes for DNA extraction.

High-molecular weight (HMW) DNA extraction of the fungal culture was based on an existing protocol $(\mathrm{Hu}$ 2016), with some modifications. About $0.6 \mathrm{~g}$ of dried fungal culture material was flash frozen with liquid nitrogen and ground with a ceramic mortar and pestle, then allowed to reach room temperature. The ground material was incubated with $500 \mu \mathrm{L}$ lysis buffer and $20 \mu \mathrm{L}$ proteinase $\mathrm{K}$ at $64{ }^{\circ} \mathrm{C}$ up to $4 \mathrm{~h}$, then cooled on ice for $5 \mathrm{~min}$. To the cool mixture, $100 \mu \mathrm{L}$ of $5 \mathrm{M}$ KAc was added and incubated for $5 \mathrm{~min}$ on ice, then centrifuged at max speed at $4{ }^{\circ} \mathrm{C}$ for $10 \mathrm{~min}$. The supernatant was added to $500 \mu \mathrm{L}$ phenol:chloroform:isoamyl alcohol and centrifuged at max speed at $4{ }^{\circ} \mathrm{C}$ for $10 \mathrm{~min}$. The supernatant was added to $500 \mu \mathrm{L}$ isopropanol and cooled at $-80^{\circ} \mathrm{C}$ for $1 \mathrm{~h}$. The isolated HMW DNA was pelleted at max speed at $4{ }^{\circ} \mathrm{C}$ for $30 \mathrm{~min}$, washed twice with $1 \mathrm{~mL}$ $70 \%$ ethanol, and eluted in $50 \mu \mathrm{L}$ TE buffer.

Isolated HMW DNA was converted into Nanopore libraries with the NBD103 and 1D library kit SQK-LSK 109. The libraries were sequenced on a SpotON R9.4.1 FLO-MIN106 flowcell for $48 \mathrm{~h}$, using a GridIONx5 sequencer. The raw sequencing data was basecalled with Guppy v3.0.3, then adaptor trimmed with Porechops v0.2.3 (https://github.com/rrwick/Porechop). In addition, 
the same DNA sample was converted into Illumina sequencing libraries with the Hyper Library construction kit from Kapa Biosystems (Roche) and paired-end sequenced for 251 cycles on a MiSeq Illumina sequencer using the MiSeq 600-cycle sequencing kit version 3. All raw Illumina reads were trimmed with Trimmomatic v0.33 (Bolger et al. 2014), setting a quality threshold of 10 (LEADING:10 TRAILING:10). Library construction and sequencing were done at the DNA services facility of the University of Illinois at Urbana-Champaign.

The long-read Nanopore sequences were assembled into continuous contigs with the program Canu v2.0 (Koren et al. 2017) and were then connected by scaffolding with the Nanopore data as a backbone using SSPACE-LongRead v1.1 (Boetzer and Pirovano 2014). These scaffolds were error corrected twice and gap filled with the Nanopore data using Racon v1.4.13 (Vaser et al. 2017) and subsequently polished twice with the trimmed MiSeq Illumina data using Pilon v1.23 (Walker et al. 2014). Genome quality was verified by mapping the long-read Nanopore and short-read Illumina sequences back to the genome with Minimap2 v2.17 (Li 2018) and BWA v0.7.17 (Li and Durbin 2009), respectively. The genome completeness was evaluated with BUSCO v4.0.6 (Seppey et al. 2019) using the dataset for Ascomycota (ascomycota_odb10). Ab initio gene modeling was performed with Augustus v3.2.3 (Hoff and Stanke 2019) using the training dataset from Aspergillus nidulans. Based on these gene models, secondary metabolites such as type I and type III polyketide synthetases (PKSs), non-ribosomal peptide synthetases (NRPSs), terpene clusters, indole clusters, and fungal-RiPP peptides were predicted using antiSMASH v5.1.2 (Blin et al. 2019). All other gene models of the Augustus prediction were annotated with DIAMOND (Buchfink et al. 2014) searches against public databases, e.g. Swissprot, trEMBL, PFAM, TIGR, HAMAP, and CDD, and subsequent manual curation of each annotation. For comparative purposes, we also constructed a de novo assembly of the trimmed short-read Illumina sequences with SPAdes v3.11.1 (Nurk et al. 2013).

Genome identity was determined with phylogenetic analyses of the internal transcribed spacer (ITS) barcoding marker sequence (Schoch et al. 2012). The ITS region was identified with a BLASTn search using the $P$. stellaris ITS sequence (AY498689) as query. The complete ITS region (ITS1, 5.8S, and ITS2) was extracted from the $P$. stellaris assembly and aligned with the ITS sequences of 31 other Physcia species downloaded from NCBI (https://www.ncbi.nlm.nih.gov/). Sequences were aligned using MAFFT v7 (Katoh and Standley 2013) and Gblocks v0.91b (Talavera and Castresana 2007) was used to delimit and remove ambiguous nucleotide positions from the alignment.
Maximum Likelihood analysis was conducted using RAxML v8.1.11 (Stamatakis 2014) on the CIPRES Science Gateway server (http://www.phylo.org/portal2). Nodal support was evaluated with 1000 bootstrap pseudoreplicates. The resulting phylogenetic tree was drawn with the program FigTree v1.4.2 (http://tree.bio.ed.ac. uk/software/figtree).

\section{Results and discussion}

We sequenced and assembled the first draft genome of the nitrogen-tolerant lichen fungus Physcia stellaris. The phylogenetic interference based on the extracted ITS region confirmed the sequenced draft genome as the lichenized fungal genome of $P$. stellaris (Fig. 6). The ITS of the sequenced genome clustered together with six other P. stellaris taxa with a bootstrap support of $90 \%$. This clade of $P$. stellaris was clearly separated from a well-supported sister clade that contained $P$. aipolia, $P$. integrata, and P. erumpens.

The genome of the lichenized fungal culture \#10-5 of $P$. stellaris assembled into 184 scaffolds with a total length of $46.57 \mathrm{Mb}$ (Table 1). Scaffolding based on the long-read Nanopore data connected 12 of 196 contigs into scaffolds. The final assembly contained 94 scaffolds larger than $100 \mathrm{~Kb}, 38$ scaffolds larger than $500 \mathrm{~Kb}$, and 6 scaffolds larger than $1 \mathrm{Mb}$. The assembly had an N50 of $594.86 \mathrm{~Kb}$ and a GC content of $43.32 \%$. The mean assembly coverage was $31.16 \mathrm{x}(\mathrm{SD}=62.35 \mathrm{x})$ of Nanopore sequences and $30.25 \mathrm{x}(\mathrm{SD}=37.36 \mathrm{x})$ of Illumina sequences. The variations in coverage of both mappings were due to smaller contigs that received lower coverage than average and the contig of the mitogenome that received much higher coverage than average. BUSCO analysis estimated a genome completeness of $95.6 \%$ by identifying 1617 complete and 3 fragmented genes from a total of 1706 Ascomycota BUSCO genes searched. Augustus predicted 10,522 genes in the assembly, resulting in an average gene density of 225.94 genes per $1 \mathrm{Mb}$. These genes were interrupted by 24,221 introns; hence each gene contained on average 2.3 introns.

The presented draft genome was sequenced and assembled from a combination of long-read Nanopore and short-read Illumina data. This hybrid assembly is highly improved compared to a short-read only assembly of $P$. stellaris that resulted in 24,595 scaffolds and a N50 of $8492 \mathrm{~Kb}$. However, other short-read draft assemblies of lichen-forming fungi resulted in larger scaffolds indicating a more complete genome structure, for example Pseudevernia furfuracea with 46 scaffolds and a N50 of $1178.8 \mathrm{~Kb}$ (Meiser et al. 2017). Pseudevernia furfuracea was sequenced with higher coverage $(\sim 350 \mathrm{x}$ vs $\sim 30 \mathrm{x}$ of Physcia stellaris). But higher sequencing coverage does not always improve genome assemblies: a second genome in the same study (Evernia prunastri) was 


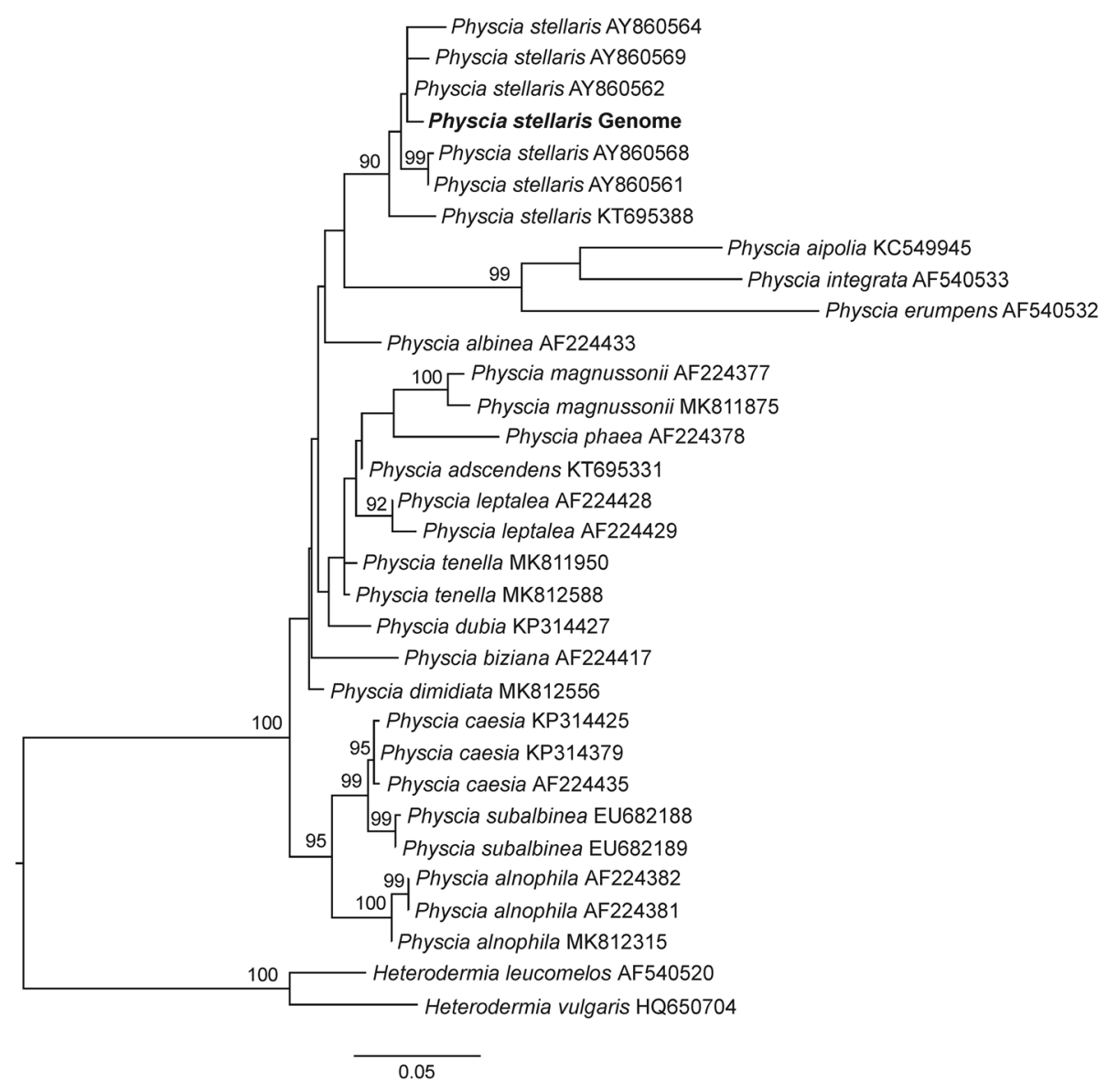

Fig. 6 Maximum Likelihood tree based on ITS sequences of Physcia species including the genome sequence of Physcia stellaris reported here (shown in bold). Bootstrap values above $75 \%$ are indicated at the nodes. Two species of Heterodermia were used as an outgroup

sequenced with higher coverage of $\sim 410 \mathrm{x}$ and resulted in a more scattered draft genome of 277 scaffolds with a N50 of $264.45 \mathrm{~Kb}$ (Meiser et al. 2017). The likely reason that some genomes assemble better than others is due to genome complexity (i.e. repetitive structures). The use of long-read sequencing improved the assembly of $P$. stellaris and solved some repetitive regions. However, other scaffolding methods such as Hi-C, linked-read technologies, or optical mapping may be required to further improve the assembly of $P$. stellaris and other repetitive fungal genomes and unravel the genomic complexity of these organisms (Thomma et al. 2016).

The genome contained 74 regions that had genes associated with secondary metabolite biosynthesis. These regions included 20 type I and a single type III polyketide synthetases (PKSs), 15 non-ribosomal peptide synthetases (NRPSs), and 16 NRPS-like fragments. In addition to these synthetases, antiSMASH identified one fungalRiPP peptide and 17 terpene, and four Indole clusters. Previous Illumina-sequenced lichenized fungal genomes had yields from 11 PKS genes in Peltigera membranacea to 32 type I PKS and 2 type III PKS genes in the genome of Cladonia uncialis (Bertrand and Sorensen 2018).

The availability of the $P$. stellaris draft genome from this study will allow comparative genomic studies within Physciaceae and will add to the genomic database of lichenized fungi for future research in evolutionary biology. Moreover, this genome will facilitate future studies in understanding the genetic mechanisms behind the adaptation to high nitrogen environments.

Authors: Felix Grewe", Isabel Distefano, Sabine Huhndorf, Yukun Sun, Claudio Ametrano, Pradeep K. Divakar, and H. Thorsten Lumbsch

"Contact: fgrewe@fieldmuseum.org

\section{IMA GENOME-F 13E}

Draft genome sequences for Australian and South American strains of Teratosphaeria pseudoeucalypti Introduction

Teratosphaeria pseudoeucalypti is a dothideomycete pathogen that was first encountered in south and central Queensland, north-western Australia (Andjic et al. 2010a). 
Table 1 General features of the genome of Physcia stellaris

\begin{tabular}{ll}
\hline Assembly statistics & Physcia stellaris 10-5 \\
\hline Assembly size (Mb) & 46.57 \\
Scaffolds & 184 \\
Contigs & 196 \\
Scaffold N50 (Kb) & 594.86 \\
Contig N50 (Kb) & 586.07 \\
Mean Coverage by Nanopore (fold) & 31.16 \\
Mean Coverage by Illumina (fold) & 30.25 \\
BUSCO coverage (\%) & 95.6 \\
G + C content (\%) & 43.32 \\
Gene prediciton statistics & \\
Predicted gene models & 10,522 \\
Average gene length (bp) & 1760.35 \\
Gene density (genes per Mb) & 225.94 \\
Predicted introns & 24,441 \\
Introns per gene & 2.32 \\
Secondary metabolites (SM) statistics & \\
Total SM clusters & 74 \\
Type I polyketide synthetases (PKSs) & 20 \\
Type III PKSs & 1 \\
Nonribosomal peptide synthetases (NRPSs) & 15 \\
NRPS-like fragments & 16 \\
Terpene clusters & 17 \\
Indole clusters & 4 \\
fungal-RiPP & 1 \\
\hline & \\
&
\end{tabular}

It is now known to be distributed across Queensland, parts of New South Wales, and in at least three South American countries (Burgess and Wingfield 2017; Andjic et al. 2019). The severe leaf-blight and defoliation of Eucalyptus trees caused by T. pseudoeucalypti is very similar to symptoms associated with $T$. destructans, one of the most aggressive of all Eucalyptus leaf pathogens (Greyling et al. 2016; Andjic et al. 2019). Leaf-spots caused by T. pseudoeucalypti have red-purple margins, similar to those caused by $T$. destructans, and range from large, confluent leaf lesions to individual necrotic leaf spots, depending on the host species and the leaf age (Andjic et al. 2010a; Ramos and Perez 2015).

Phylogenetically, T. pseudoeucalypti resides within an economically important clade of Teratosphaeria leaf pathogens that also includes T. destructans and T. nubilosa (Aylward et al. 2019). It is sister to T. eucalypti and was initially mistaken for that species because of their similar spore morphologies (Andjic et al. 2010a). Based on PCR amplification of mating type genes, most species in this clade are believed to be heterothallic (Havenga et al. 2020), with the notable exception of T. nubilosa (Pérez et al. 2010).

Subsequent to its description in 2010, T. pseudoeucalypti emerged in the neighbouring regions of Brazil (Cândido et al. 2014), Uruguay (Soria et al. 2014), and Argentina (Ramos and Perez 2015) in rapid succession. Although it was known in tropical and subtropical regions of eastern Australia, the South American hosts included temperate species such as E. globulus (Cerasoli et al. 2016). It is, therefore, of concern that T. pseudoeucalypti, unlike $T$. destructans, presents a threat to coldtolerant Eucalyptus clones.

Teratosphaeria pseudoeucalypti is an aggressive pathogen with the potential to infect numerous Eucalyptus species across different climatic zones. Knowledge of its life-cycle and genetic diversity is required to manage the current disease outbreaks and to prepare for future disease problems. The aim of this study was to generate whole genome sequences, for both mating types of $T$. pseudoeucalypti, that will serve as a resource from which to design molecular markers and to conduct whole genome comparisons.

\section{Sequenced strains}

Uruguay: Colonia, isolated from spots on Eucalyptus camaldulensis leaves, Apr. 2015, C. Pérez (CMW 49159 = UY2039 - culture).

Uruguay: Durazno, isolated from spots on the leaves of a Eucalyptus hybrid, May 2015, C. Pérez (CMW 49161 = UY2151 - culture).

Australia: Queensland: Miriam Vale: isolated from spots on the leaves of Eucalyptus grandis $\times$ E. camaldulensis, 2005, G. Pegg (CMW 51515 = MUCC610 - culture).

\section{Nucleotide accession number}

The genomic sequences of these T. pseudoeucalypti isolates have been deposited at DDJ/EMBL/GenBank under the accessions JABASB000000000, JABBMY000000000 and JABBMZ000000000. This paper describes the first versions of these genomes.

\section{Material and methods}

Fungal cultures are maintained in the collections of the Forestry and Agricultural Biotechnology Institute (CMW), University of Pretoria, South Africa, the EEMAC laboratory (UY), Facultad de Agronomia, Universidad de la Republica, Uruguay and the Murdoch University culture collection (MUCC), Australia. Cultures were grown on malt extract agar (Merck, Wadeville, South Africa) at $25^{\circ} \mathrm{C}$ in the dark. After approximately $2 \mathrm{wk}$., mycelial mats were transferred to $2 \mathrm{ml}$ Eppendorf tubes and freeze dried. DNA was extracted following the protocol used for T. destructans (Wingfield et al. 2018b). A NanoDrop ND-1000 
spectrophotometer (ThermoFisher Scientific, Wilmington, VA) and Qubit $^{\circ}$ 2.0 Fluorometer (Invitrogen, Carlsbad, CA) were used to estimate the quality and quantity (respectively) of the extracted DNA.

All three T. pseudoeucalypti isolates were sequenced using the Illumina HiSeq 2500 platform at Macrogen (Seoul, Korea). The paired-end Illumina libraries for the two Uruguayan isolates (CMW49159 and CMW49161) had insert sizes of $350 \mathrm{bp}$ and the target read length was $100 \mathrm{bp}$. Genome assembly was performed with SPAdes v3.12.0, applying k-values of 21, 33 and 55. Low coverage sequencing for the Australian isolate (CMW51515) was conducted using a $550 \mathrm{bp}$ insert library and a read length of $250 \mathrm{bp}$. This isolate was assembled with SPAdes v3.14.0 and k-values 21, 33, 55, 77, 99 and 127. For all three isolates, read correction was performed with Trimmomatic v0.39 (Bolger et al. 2014) and the MismatchCorrector option was turned on during the SPAdes assembly. Genome coverage was calculated by aligning the raw reads to the assembled genomes with Bowtie v1.2.2 (Langmead et al. 2009) and determining depth with Mosdepth v0.2.7 (Pedersen and Quinlan 2018), while genome completeness was estimated with BUSCO v3.0.2 (Waterhouse et al. 2017) using the Fungi, Ascomycota, and Capnodiales datasets.

Genome annotation procedures, including repeatfinding, followed those described by Wingfield et al. (2019) for T. gauchensis and T. zuluensis. The putative mating type (MAT1) locus was identified by performing a BLASTn search against the genomes with the MAT1-1 and MAT1-2 idiomorphs of T. destructans as query sequences (GenBank accessions MN531144 and MN531145; Havenga et al. 2020). For phylogenetic analysis, we used the beta-tubulin, translation elongation factor-1 $\alpha$ (EF-1 $\alpha)$ and internal transcribed spacer (ITS) gene regions. Alignment and curation was performed on the NGPhylogeny.fr platform (Lemoine et al. 2019) using MAFFT 7.407_1 (Katoh and Standley 2013) and Gblocks 0.91.1 (Talavera and Castresana 2007). Alignments were concatenated with FASconCAT-G (Kück and Longo 2014), the best-fit nucleotide substitution model for each partition was determined with ModelTest-NG (Darriba et al. 2020) and a maximum likelihood phylogeny was calculated with RAxML-NG 0.9.0 (Kozlov et al. 2019).

\section{Results and discussion}

In the phylogeny based on concatenated beta-tubulin, EF- $1 \alpha$ and ITS sequences (Fig. 7), the three isolates selected for genome sequencing formed a well-supported (96\%) clade with T. pseudoeucalypti isolates from across the distribution range of this species. Taxonomic relationships mirrored those previously described for species in this clade of economically important Teratosphaeria leaf pathogens (Quaedvlieg et al. 2014). The sister relationship between T. pseudoeucalypti and T. eucalypti was not resolved in this analysis, but has been supported in previous studies (Andjic et al. 2010b; Soria et al. 2014).

\section{Tree Scale: 0.1}

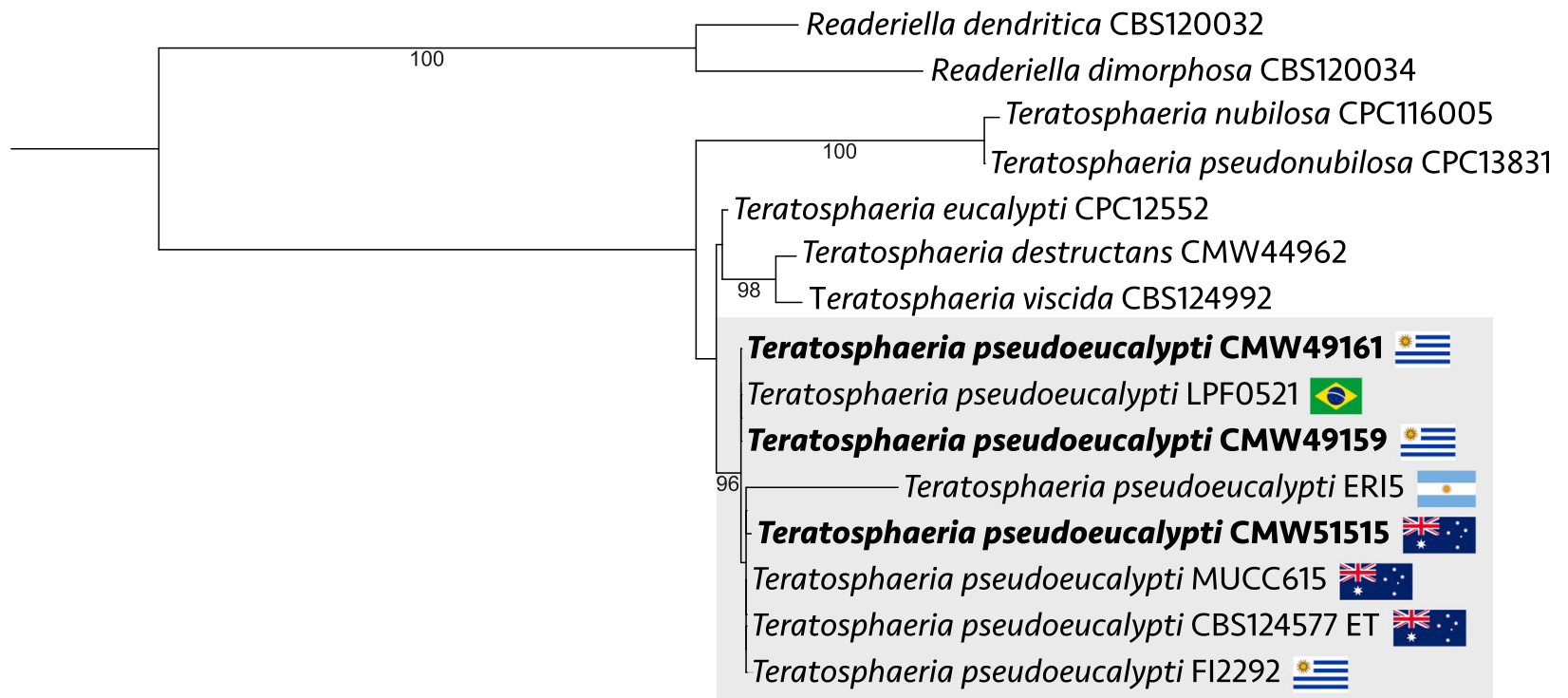

Fig. 7 Maximum likelihood phylogeny of Teratosphaeria pseudoeucalypti and other closely related foliar pathogens. Isolates collected from the four countries in which T. pseudoeucalypti is known were included. Apart from the genomes generated in this study (shown in bold), the gene sequences were sourced from previous studies (Andjic et al. 2010a; Quaedvlieg et al. 2014; Soria et al. 2014; Ramos and Perez 2015; Aylward et al. 2019). ET= ex-type strain 
The genome assemblies of the T. pseudoeucalypti isolates from Uruguay were $26.8 \mathrm{Mb}$ with $>100 \mathrm{x}$ coverage, whereas the assembly of the Australian isolate totaled $30.2 \mathrm{Mb}$ with approximately $22 \mathrm{x}$ coverage. The number of scaffolds, N50 and L50 was in the same range for all three genomes (Table 2). The difference in genome size is likely due to the different read lengths that were generated and used for genome assembly. Since the Australian isolate was sequenced with $250 \mathrm{bp}$ reads, compared to $100 \mathrm{bp}$ reads for the Uruguayan isolates, a greater number of repetitive regions would have been resolved in the genome assembly of the Australian isolate, hence its larger genome size.

An analysis of the repetitive regions in these genomes supported the conclusion that read length may be the cause of the difference in genome size observed. The Australian genome was $12.3 \%$ repetitive, whereas repetitive regions comprised only $2.3 \%$ of the other two genomes. A repeat content of $12.3 \%$ would be closer to the $17 \%$ estimated for the closely related leaf pathogen $T$. destructans, whereas lower repeat contents (ca. 2\%) resemble those of the stem canker pathogens T. gauchensis and T. zuluensis (Wingfield et al. 2018b, 2019).

The three $T$. pseudoeucalypti genomes had a similar number of predicted genes, especially when considering the gene predictions that were similar to the proteins or

Table 2 Assembly and annotation statistics ${ }^{\text {a }}$ for the Teratosphaeria pseudoeucalypti genomes

\begin{tabular}{|c|c|c|c|}
\hline & CMW49159 & CMW49161 & CMW51515 \\
\hline \multicolumn{4}{|l|}{ Isolate information } \\
\hline Origin & Uruguay & Uruguay & Australia \\
\hline Mating type & MAT1-1 & MAT1-1 & MAT1-2 \\
\hline \multicolumn{4}{|l|}{ Genome assembly } \\
\hline Assembly size (Mb) & 26.78 & 26.79 & 30.24 \\
\hline Number of scaffolds & 630 & 622 & 608 \\
\hline N50 (kb) & 166.471 & 181.549 & 183.627 \\
\hline L50 & 44 & 43 & 52 \\
\hline Estimated coverage & $\times 150$ & $\times 120$ & $\times 22$ \\
\hline GC content & $54.2 \%$ & $54.2 \%$ & $52.0 \%$ \\
\hline \multicolumn{4}{|l|}{ Genome annotation } \\
\hline Supported $^{\mathrm{b}}$ gene predictions & 8879 & 8865 & 8870 \\
\hline $\begin{array}{l}\text { Unsupported gene } \\
\text { predictions }\end{array}$ & 1356 & 1384 & 1569 \\
\hline Repetitive regions & $2.3 \%$ & $2.3 \%$ & $12.25 \%$ \\
\hline \multicolumn{4}{|l|}{ BUSCO Genome completeness } \\
\hline Fungi odb10 & $98.94 \%$ & $98.68 \%$ & $98.68 \%$ \\
\hline Ascomycota odb10 & $98.01 \%$ & $98.18 \%$ & $96.83 \%$ \\
\hline Capnodiales odb10 & $93.21 \%$ & $93.15 \%$ & $94.46 \%$ \\
\hline
\end{tabular}

${ }^{a}$ All statistics are based on scaffolds $>499 \mathrm{bp}$

${ }^{\text {bS }}$ upported by external protein or EST evidence

'Predicted by de novo gene predictors, but without external evidence
CDS sequences of other species ( $~ 8870$ predictions). A further 1356-1569 genes that did not have such external evidence were also predicted in the three species. Based on gene orthologs that should be present in certain taxa, the predicted completeness of the three genomes ranged from $93.2 \%$ at the highest taxonomic level (Capnodiales) to $98.9 \%$ at the lowest level (Fungi). The $M A T$ idiomorphs in all three T. pseudoeucalypti isolates had $>96 \%$ nucleotide identity to the $T$. destructans MAT1 idiomorphs and, therefore, resembled the MAT1 loci of other heterothallic Teratosphaeria species (Aylward et al. 2020; Havenga et al. 2020). In the genomes of the two Uruguayan isolates, the $M A T 1-1$ idiomorph consisted of the MAT1-1-1 and MAT1-1-10 genes, whereas the MAT1-2 idiomorph in the genome of the Australian isolate comprised the MAT1-2-1 and MAT1-2-12 genes.

Teratosphaeria pseudoeucalypti is the third Teratosphaeria foliar pathogen, after $T$. destructans (Wingfield et al. 2018b; Havenga et al. 2020) and T. nubilosa (Abdollahzadeh et al. 2020), for which whole genome sequence data are available. The T. pseudoeucalypti genomes generated in this study will be used to develop genetic markers to study the diversity of T. pseudoeucalypti outbreaks and to compare this pathogen with its closest relatives. Along with the genomes of $T$. destructans, $T$. nubilosa and the stem canker pathogens, T. gauchensis and T. zuluensis (Wingfield et al. 2019), the data generated in this study contribute to a growing database of knowledge concerning Eucalyptus disease-causing fungi.

Authors: Janneke Aylward\%, Tuan A. Duong, Brenda D. Wingfield, Nazaret Ramírez-Berrutti, Carlos A. Pérez, and Michael J. Wingfield

*Contact: Janneke.Aylward@fabi.up.ac.za
Acknowledgements

The authors of the contributions on Teratosphaeria thank Treena Burgess and Vera Andjic for supplying the Australian Teratosphaeria isolate that was sequenced.

The authors of the contribution on Physcia thank Susan and David Milligan for their generous donation to the Pritzker Laboratory for Molecular Systematics and Evolution at the Field Museum, Chicago.

For the contributions on Cercospora species, SS is thankful to Council of Scientific and Industrial Research (CSIR), New Delhi, India for Junior Research Fellowship (JRF), SS and RNK are thankful to Head and Coordinator, CAS in Botany, BHU for infrastructure facilities; to Coordinators, DBT- Interdisciplinary School of Life Sciences (ISLS), Department of Science and TechnologyPromotion of University Research and Scientific Excellence (DST-PURSE), UGC- University with Potential for Excellence (UPE), at Banaras Hindu University, Varanasi, for technical and minor help.
Authors' contributions

In the contributions on Cercospora, RC, RNK and SN planned the experiment. $\mathrm{RC}$ and SS contributed to isolation and morphology. SN and SS contributed to sequencing and drafted the manuscript. SN contributed to data analysis. RNK reviewed the second manuscript and added corrections, and RS contributed to the identification of the isolate. All authors read and approved the manuscripts. 


\section{Funding}

The authors of the contributions on Ambrosiella and Teratosphaeria thank the University of Pretoria, the Tree Protection Co-operative Programme (TPCP), the DSI-NRF Centre of Excellence in Plant Health Biotechnology, the National Research Foundation and the DSI-NRF SARChl chair in Fungal Genomics for their financial support. Those of that on Physcia thank the Grainger Bioinformatics Center at the Field Museum, Chicago for its support.

\section{Availability of data and materials}

All data and materials are available in data banks and culture collections and fungaria, respectively. Relevant details are given in the contributions.

\section{Ethics approval and consent to participate}

Not applicable, as neither humans and human subjects or data were used in this manuscript.

\section{Consent for publication}

Not applicable.

\section{Competing interests}

The authors declare that they have no competing interests.

\section{Author details}

'Department of Biochemistry, Genetics and Microbiology, Forestry and Agricultural Biotechnology Institute (FABI), University of Pretoria, Private Bag x20, Hatfield, Pretoria 0028, South Africa. ${ }^{2}$ Department of Conservation Ecology and Entomology, Stellenbosch University, Private Bag X1, Matieland 7602, South Africa. ${ }^{3}$ Institute of Agricultural Sciences, Banaras Hindu University, Varanasi 221005, India. ${ }^{4}$ Field Museum, Department of Science and Education, Grainger Bioinformatics Center, Chicago, IL, USA. ${ }^{5}$ Center of Advanced Study in Botany, Institute of Science, Banaras Hindu University, Varanasi 221005, India. ${ }^{6}$ Departamento de Farmacología, Farmacognosia y Botánica, Facultad de Farmacia, Universidad Complutense de Madrid, Plaza de Ramón y Cajal s/n, 28040 Madrid, Spain. ${ }^{7}$ Agharkar Research Institute, G.G. Agharkar Road, Pune 411004, India. ${ }^{8}$ Department of Plant Protection, EEMAC, Facultad de Agronomía, UdelaR, Paysandú, Uruguay. ${ }^{9}$ National Centre for Microbial Resource, National Centre for Cell Science, S.P, Pune University, Pune 411 007, India.

\section{Published online: 24 September 2020}

\section{REFERENCES}

Abdollahzadeh J, Groenewald J, Coetzee M, Wingfield M, Crous P (2020)

Evolution of lifestyles in Capnodiales. Studies in Mycology in press

Albu S, Sharma S, Bluhm BH, Price PP, Schneider RW, Doyle VP (2017) Draft genome sequence of Cercospora cf. sigesbeckiae, a causal agent of Cercospora leaf blight on soybean. Genome Announcements 5:e00708e00717

Altschul SF, Gish W, Miller W, Myers EW, Lipman DJ (1990) Basic local alignment search tool. Journal of Molecular Biology 215:403-410

Andjic V, Carnegie AJ, Pegg GS, Hardy GESJ, Maxwell A, Crous PW, Pérez C, Wingfield MJ, Burgess TI (2019) 23 years of research on Teratosphaeria leaf blight of Eucalyptus. Forest Ecology and Management 443:19-27

Andjic V, Pegg GS, Carnegie AJ, Callister A, Hardy GE, Burgess TI (2010a) Teratosphaeria pseudoeucalypti, new cryptic species responsible for leaf blight of Eucalyptus in subtropical and tropical Australia. Plant Pathology 59: 900-912

Andjic V, Whyte G, Hardy G, Burgess TI (2010b) New Teratosphaeria species occurring on eucalypts in Australia. Fungal Diversity 43:27-38

Andrews S (2010) FastQC: a quality control tool for high throughput sequence data. http://www.bioinformatics.babraham.ac.uk/projects/fastqc

Anisimova M, Gascuel O (2006) Approximate likelihood ratio test for branches: a fast, accurate and powerful alternative. Systematic Biology 55:539-552

Aylward J, Havenga M, Dreyer LL, Roets F, Wingfield BD, Wingfield MJ (2020) Genomic characterization of mating type loci and mating type distribution in two apparently asexual plantation tree pathogens. Plant Pathology 69:28-37

Aylward J, Roets F, Dreyer LL, Wingfield MJ (2019) Teratosphaeria stem canker of Eucalyptus: two pathogens, one devastating disease. Molecular Plant Pathology 20:8-19
Bankevich A, Nurk S, Antipov D, Gurevich AA, Dvorkin M et al (2012) SPAdes: a new genome assembly algorithm and its applications to single-cell sequencing. Journal of Computational Biology 19:455-477

Batra LR (1963) Ecology of ambrosia fungi and their dissemination by beetles. Transactions of the Kansas Academy of Science 66:213-236

Belova T, Zhan B, Wright J, Caccamo M, Asp T et al (2013) Integration of mate pair sequences to improve shotgun assemblies of flow-sorted chromosome arms of hexaploid wheat. BMC Genomics 14:222

Bertrand RL, Sorensen JL (2018) A comprehensive catalogue of polyketide synthase gene clusters in lichenizing fungi. Journal of Industrial Microbiology and Biotechnology 45:1067-1081

Blin K, Shaw S, Steinke K et al (2019) AntiSMASH 5.0: updates to the secondary metabolite genome mining pipeline. Nucleic Acids Research 47:W81-W87

Boetzer M, Pirovano W (2014) SSPACE-LongRead: scaffolding bacterial draft genomes using long read sequence information. BMC Bioinformatics 15:1-9

Bolger AM, Lohse M, Usadel B (2014) Trimmomatic: a flexible trimmer for Illumina sequence data. Bioinformatics 30:2114-2120

Boltersdorf SH, Werner W (2014) Lichens as a useful mapping tool? - an approach to assess atmospheric $\mathrm{N}$ loads in Germany by total $\mathrm{N}$ content and stable isotope signature. Environmental Monitoring and Assessment 186: 4767-4778

Buchfink B, Xie C, Huson DH (2014) Fast and sensitive protein alignment using DIAMOND. Nature Methods 12:59-60

Burgess TI, Wingfield MJ (2017) Pathogens on the move: a 100-year global experiment with planted eucalypts. Bioscience 67:14-25

Cândido TDS, Da Silva AC, Guimarães LMDS, Ferraz HGM, Borges Júnior N, Alfenas AC (2014) Teratosphaeria pseudoeucalypti on eucalyptus in Brazil. Trop Plant Pathol 39:407-412

Castresana J (2000) Selection of conserved blocks from multiple alignments for their use in phylogenetic analysis. Molecular Biology and Evolution 17:540552

Cerasoli S, Caldeira MC, Pereira JS, Caudullo G, De Rigo D (2016) Eucalyptus globulus and other eucalypts in Europe: distribution, habitat, usage and threats. In: San-Miguel-Ayanz J, De Rigo D, Caudullo G, Houston Durrant T, Mauri A (eds) European atlas of forest tree species. Publishing Office of the EU, Luxembourg

Chand R, Pal C, Singh V, Kumar M, Singh VK, Chowdappa P (2015) Draft genome sequence of Cercospora canescens a leaf spot causing pathogen. Current Science 109:2103-2110

Chupp C (1954) A monograph of the fungus genus Cercospora. Ithaca, New York

Conti ME, Cecchetti G (2001) Biological monitoring: lichens as bioindicators of air pollution assessment - a review. Environmental Pollution 114:471-492

Darriba D, Posada D, Kozlov AM, Stamatakis A, Morel B, Flouri T (2020) ModelTestNG: a new and scalable tool for the selection of DNA and protein evolutionary models. Molecular Biology and Evolution 37:291-294

Dereeper A, Audic S, Claverie JM, Blanc G (2010) BLAST-EXPLORER helps you building datasets for phylogenetic analysis. BMC Evolutionary Biology 10:8

Dereeper A, Guignon V, Blanc G, Audic S, Buffet S et al (2008) Phylogeny.fr: robust phylogenetic analysis for the non-specialist. Nucleic Acids Research 36:W465-W469

Dyer PS, O'Gorman CM (2012) Sexual development and cryptic sexuality in fungi: insights from Aspergillus species. FEMS Microbiology Reviews 36:165-192

Edgar RC (2004) MUSCLE: multiple sequence alignment with high accuracy and high throughput. Nucleic Acids Research 32:1792-1797

Elix JA, Corush J, Lumbsch HT (2009) Triterpene chemosyndromes and subtle morphological characters characterise lineages in the Physcia aipolia group in Australia (Ascomycota). Systematics and Biodiversity 7:479-487

Ene IV, Bennett RJ (2014) The cryptic sexual strategies of human fungal pathogens. Nature Reviews Microbiology 12:239-251

Estrabou C, Filippini E, Soria JP et al (2011) Air quality monitoring system using lichens as bioindicators in Central Argentina. Environmental Monitoring and Assessment 182:375-383

Farrell BD, Sequeira AS, O'Meara BC, Normark BB, Chung JH et al (2001) The evolution of agriculture in beetles (Curculionidae: Scolytinae and Platypodinae). Evolution 55:2011-2027

Greyling I, Wingfield MJ, Coetzee MPA, Marincowitz S, Roux J (2016) The Eucalyptus shoot and leaf pathogen Teratosphaeria destructans recorded in South Africa. Southern Forests: a Journal of Forest Science 78:123-129

Groenewald JZ, Nakashima C, Nishikawa J, Shin HD, Park JH, Jama AN, Groenewald M, Braun U Crous PW (2013) Species concepts in Cercospora: spotting the weeds among the roses. Studies in Mycology 75:115-170 
Guindon S, Gascuel O (2003) A simple, fast, and accurate algorithm to estimate large phylogenies by maximum likelihood. Systematic Biology 52:696-704

Gurevich A, Saveliev V, Vyahhi N, Tesler G (2013) QUAST: a quality assessment tool for genome assemblies. Bioinformatics 29:1072-1075

Harrington TC (2005) Ecology and evolution of mycophagous bark beetles and their fungal partners. In: Vega FE, Blackwell M (eds) Ecological and evolutionary advances in insect-fungal associations. Oxford University Press, New York, pp 257-291

Harrington TC, McNew D, Mayers C, Fraedrich SW, Reed SE (2014) Ambrosiella roeperi sp. nov. is the mycangial symbiont of the granulate ambrosia beetle, Xylosandrus crassiusculus. Mycologia 106:835-845

Havenga M, Wingfield BD, Wingfield MJ, Roets F, Dreyer LL, Tatham CT, Duong TA, Wilken PM, Chen S, Aylward J (2020) Mating strategy and mating type distribution in six global populations of the Eucalyptus foliar pathogen Teratosphaeria destructans. Fungal Genetics and Biology 137:103350

Hoff KJ, Stanke M (2019) Predicting genes in single genomes with AUGUSTUS. Current Protocols in Bioinformatics 65:1-54

Hsieh WH, Goh TK (1990) Cercospora and similar fungi from Taiwan. Maw Chang Book Company, Taipei

Hu Y (2016) High quality DNA extraction from Fungi_small scale. Protocols.lo. https://doi.org/dx.doi.org/10.17504/protocols.io.exmbfk6

Hyerczyk RD (2005) The lichen flora of ten Chicago parks, Chicago Park district, Chicago, Illinois. Transactions of the Illinois Academy of Sciences 98:97-122

Janssen A-M, Jan-Peter F, Heidelbach B (2007) Die Entwicklung der Flechtenvegetation in Bonn 2003-2006. Delcheniana XX:155-157

Jovan S, Riddell J, Padgett PE, Nash TH (2012) Eutrophic lichens respond to multiple forms of $\mathrm{N}$ : implications for critical levels and critical loads research. Ecological Applications 22:1910-1922

Kahn BA, Damicone JP, Schatzer RJ (2005) Alternatives to benomyl for management of Cercospora leaf spot on turnip greens. HortScience 40:1324-1326

Kamal (2010) Cercosporoid Fungi of India. Bishen Singh Mahendra Pal Singh, Dehradun

Katoh K, Standley DM (2013) MAFFT multiple sequence alignment software version 7: improvements in performance and usability. Molecular Biology and Evolution 30:772-780

Keller O, Kollmar M, Stanke M, Waack S (2011) A novel hybrid gene prediction method employing protein multiple sequence alignments. Bioinformatics 27 : 757-763

Koren S, Walenz BP, Berlin K et al (2017) Canu: scalable and accurate long-read assembly via adaptive $\mathrm{k}$-mer weighting and repeat separation. Genome Research 27:722-736

Kozlov AM, Darriba D, Flouri T, Morel B, Stamatakis A (2019) RAxML-NG: a fast, scalable and user-friendly tool for maximum likelihood phylogenetic inference. Bioinformatics 35:4453-4455

Kück P, Longo GC (2014) FASconCAT-G: extensive functions for multiple sequence alignment preparations concerning phylogenetic studies. Frontiers in Zoology 11:81

Kück U, Pöggeler S (2009) Cryptic sex in fungi. Fungal Biology Reviews 23:86-90

Kumar S, Stecher G, Tamura K (2016) MEGA7: molecular evolutionary genetics analysis version 7.0 for bigger datasets. Molecular Biology and Evolution 33: 1870-1874

Langmead B, Trapnell C, Pop M, Salzberg SL (2009) Ultrafast and memoryefficient alignment of short DNA sequences to the human genome. Genome Biology 10:R25

Langston DB Jr, Boland RT Jr, Price JG (2005) Evaluation of fungicides for control of Cercospora leaf spot of the turnip, pp 88-89

Lemoine F, Correia D, Lefort V, Doppelt-Azeroual O, Mareuil F, Cohen-Boulakia S, Gascuel O (2019) NGPhylogeny. Fr: new generation phylogenetic services for non-specialists. Nucleic Acids Research 47:W260-W265

Li H (2018) Minimap2: pairwise alignment for nucleotide sequences. Bioinformatics 34:3094-3100

Li H, Durbin R (2009) Fast and accurate short read alignment with burrowswheeler transform. Bioinformatics 25:1754-1760

Lin YT, Shih HH, Hulcr J, Lin CS, Lu SS et al (2017) Ambrosiella in Taiwan including one new species. Mycoscience 58:242-252

Little S (1987) Cercospora citrullina. CMI Descriptions of Pathogenic Fungi and Bacteria 917:1-2

Lohtander K, Källersjö M, Moberg R, Tehler A (2000) The family Physciaceae in Fennoscandia: phylogeny inferred from ITS sequences. Mycologia 92: 728-735
Lohtander K, Myllys L, Källersjö M et al (2009) New entities in Physcia aipolia P. caesia group (Physciaceae, ascomycetes): an analysis based on mtSSU, ITS, group I intron and betatubulin sequences. Annales Botanici Fennici 46:43-53

Lücking R, Hodkinson BP, Leavitt SD (2017) The 2016 classification of lichenized fungi in the Ascomycota and Basidiomycota - approaching one thousand genera. Bryologist 119:361

Mayers CG, Harrington TC, Masuya H, Jordal BH, McNew DL et al (2019) Patterns of coevolution between ambrosia beetle mycangia and the Ceratocystidaceae, with five new fungal genera and seven new species. Persoonia 44:41-66

Mayers CG, Harrington TC, Ranger CM (2017) First report of a sexual state in an ambrosia fungus: Ambrosiella cleistominuta sp. nov. associated with the ambrosia beetle Anisandrus maiche. Botany 95:503-512

Mayers CG, McNew DL, Harrington TC, Roeper RA, Fraedrich SW et al (2015) Three genera in the Ceratocystidaceae are the respective symbionts of three independent lineages of ambrosia beetles with large, complex mycangia. Fungal Biology 119:1075-1092

Meiser A, Otte J, Schmitt I, Grande FD (2017) Sequencing genomes from mixed DNA samples - evaluating the metagenome skimming approach in lichenized fungi. Scientific Reports 7:1-13

Miadlikowska J, Kauff F, Högnabba F et al (2014) A multigene phylogenetic synthesis for the class Lecanoromycetes (Ascomycota): 1307 fungi representing 1139 infrageneric taxa, 317 genera and 66 families. Molecular Phylogenetics and Evolution 79:132-168

Mikheenko A, Prjibelski A, Saveliev V, Antipov D, Gurevich A (2018) Versatile genome assembly evaluation with QUAST-LG. Bioinformatics 34:i142-i150

Moberg R (2002) Nordic Lichen Flora.Vol.2: Physciaceæ. TH-tryck, Uddevalla

Murray MG, Thompson WF (1980) Rapid isolation of high molecular weight plant DNA. Nucleic Acids Research 8:4321-4326

Nguanhom J, Cheewangkoon R, Groenewald JZ, Braun U, To-Anun C, Crous PW (2015) Taxonomy and phylogeny of Cercospora spp. from northern Thailand. Phytotaxa 233:27-48

Nimis P, Lazzarin A, Lazzarin G, Gasparo D (1991) Lichens as bioindicators of air pollution by $\mathrm{SO} 2$ in the Veneto region (NE ITALY). Studia Geobotanica 11:3-76

Nurk $S$ et al (2013) Assembling genomes and mini-metagenomes from highly chimeric reads. In: Deng M, Jiang R, Sun F, Zhang X (eds) Research in computational molecular biology. RECOMB 2013. Lecture notes in computer science, vol 7821. Springer, Berlin

Orner VA, Cantonwine EG, Wang XM, Abouelleil A, Bochicchio J, Nusbaum C, Culbreath AK, Abdo Z, Arias RS (2015) Draft genome sequence of Cercospora arachidicola, the causal agent of early leaf spot in peanuts. Genome Announcements 3:e01281-e01215

Paoletti M, Rydholm C, Schwier EU, Anderson MJ, Szakacs G et al (2005) Evidence for sexuality in the opportunistic fungal pathogen Aspergillus fumigatus. Current Biology 15:1242-1248

Pedersen BS, Quinlan AR (2018) Mosdepth: quick coverage calculation for genomes and exomes. Bioinformatics 34:867-868

Pérez G, Slippers B, Wingfield BD, Hunter GC, Wingfield MJ (2010) Micro-and macrospatial scale analyses illustrates mixed mating strategies and extensive geneflow in populations of an invasive haploid pathogen. Molecular Ecology 19:1801-1813

Quaedvlieg W, Binder M, Groenewald JZ, Summerell BA, Carnegie AJ, Burgess TI, Crous PW (2014) Introducing the consolidated species concept to resolve species in the Teratosphaeriaceae. Persoonia 33:1-40

Ramos SO, Perez CA (2015) First report of Teratosphaeria pseudoeucalypti on Eucalyptus hybrids in Argentina. Plant Disease 99:554-554

Ranger CM, Schultz PB, Frank SD, Chong JH, Reding ME (2015) Non-native ambrosia beetles as opportunistic exploiters of living but weakened trees. PLoS One 10:e0131496

Rindita, Sudirman LI, Koesmaryono Y (2015) Air quality bioindicator using the population of epiphytic macrolichens in Bogor City, West Java. HAYATI Journal of Biosciences 22:53-59

Saitou N, Nei M (1978) The neighbor-joining method: a new method for reconstructing phylogenetic trees. Molecular Biology and Evolution 4:406-425

Sautua FJ, Gonzalez SA, Doyle VP, Berretta MF, Gordó M, Scandiani MM, Rivarola ML, Fernandez P, Carmona MA (2019) Draft genome sequence data of Cercospora kikuchii, a causal agent of Cercospora leaf blight and purple seed stain of soybeans. Data in Brief 27:104693

Sayari M, van der Nest MA, Steenkamp ET, Soal NC, Wilken PM et al (2019) Distribution and evolution of nonribosomal peptide synthetase gene clusters in the Ceratocystidaceae. Genes 10:328 
Schoch CL, Seifert KA, Huhndorf S et al (2012) Nuclear ribosomal internal transcribed spacer (ITS) region as a universal DNA barcode marker for Fungi. Proceedings of the National Academy of Science of the United States 109: 6241-6246

Schubert M, Lindgreen S, Orlando L (2016) AdapterRemoval v2: rapid adapter trimming, identification, and read merging. BMC Research Notes 9:88

Seppey M, Manni M, Zdobnov EM (2019) BUSCO: assessing genome assembly and annotation completeness. In: Methods in molecular biology, pp 227-245

Simão FA, Waterhouse RM, loannidis P, Kriventseva EV, Zdobnov EM (2015) BUSCO: assessing genome assembly and annotation completeness with single-copy orthologs. Bioinformatics 31:3210-3212

Simon DM, Hummel CL, Sheeley SL, Bhattacharya D (2005) Heterogeneity of intron presence or absence in rDNA genes of the lichen species Physcia aipolia and P. stellaris. Current Genetics 47:389-399

Simpson MC, Coetzee MPA, van der Nest MA, Wingfield MJ, Wingfield BD (2018) Ceratocystidaceae exhibit high levels of recombination at the mating-type (MAT) locus. Fungal Biology 122:1184-1191

Soria S, Alonso R, Bettucci L, Lupo S (2014) First report of Teratosphaeria pseudoeucalypti in Uruguay. Australasian Plant Disease Notes 9:146

Stamatakis A (2014) RAxML version 8: a tool for phylogenetic analysis and postanalysis of large phylogenies. Bioinformatics 30:1312-1313

Stamenković S, Cvijan M, Arandjelović M (2010) Lichens as bioindicators of air quality in Dimitrovgrad (South-Eastern Serbia). Archives of Biological Sciences Belgrade 62:643-648

Stanke M, Morgenstern B (2005) AUGUSTUS: a web server for gene prediction in eukaryotes that allows user-defined constraints. Nucleic Acids Research 33 : 465-467

Stanke M, Tzvetkova A, Morgenstern B (2006) AUGUSTUS at EGASP: using EST, protein and genomic alignments for improved gene prediction in the human genome. Genome Biology 7:S11

Talavera G, Castresana J (2007) Improvement of phylogenies after removing divergent and ambiguously aligned blocks from protein sequence alignments. Systematic Biology 56:564-577

Thomma BPHJ, Seidl MF, Shi-Kunne X et al (2016) Mind the gap; seven reasons to close fragmented genome assemblies. Fungal Genetics and Biology 90: 24-30

van der Nest MA, Steenkamp ET, McTaggart AR, Trollip C, Godlonton T et al (2015) Saprophytic and pathogenic fungi in the Ceratocystidaceae differ in their ability to metabolize plant-derived sucrose. BMC Evolutionary Biology $15: 273$

van der Nest MA, Steenkamp ET, Roodt D, Soal NC, Palmer M et al (2019) Genomic analysis of the aggressive tree pathogen Ceratocystis albifundus. Fungal Biology 123:351-363

van Heesch S, Kloosterman WP, Lansu N, Ruzius FP, Levandowsky E et al (2013) Improving mammalian genome scaffolding using large insert mate-pair nextgeneration sequencing. BMC Genomics 14:1-11

Van Herk CM, Mathijssen-Spiekman EAM, De Zwart D (2003) Long distance nitrogen air pollution effects on lichens in Europe. Lichenologist 35:347-359

Vanderpool D, Bracewell RR, McCutcheon JP (2017) Know your farmer: ancient origins and multiple independent domestications of ambrosia beetle fungal cultivars. Molecular Ecology 27:2077-2094

Vaser R, Sović I, Nagarajan N, Šikić M (2017) Fast and accurate de novo genome assembly from long uncorrected reads. Genome Research 27:737-746

Walker BJ, Abeel T, Shea T et al (2014) Pilon: an integrated tool for comprehensive microbial variant detection and genome assembly improvement. PLoS One 9:e112963

Waterhouse RM, Seppey M, Simão FA, Manni M, loannidis P, Klioutchnikov G, Kriventseva EV, Zdobnov EM (2017) BUSCO applications from quality assessments to gene prediction and phylogenomics. Molecular Biology and Evolution 35:543-548

White TJ, Bruns T, Lee S, Taylor J (1990) Amplification and direct sequencing of fungal ribosomal RNA genes for phylogenetics. In: Innis MA, Gelfand DH, Sninsky JJ, White YJ (eds) PCR protocols: a guide to methods and applications. Academic Press, San Diego, pp 315-322

Wibberg D, Rupp O, Jelonek L, Kröber M, Verwaaijen B et al (2015) Improved genome sequence of the phytopathogenic fungus Rhizoctonia solani AG1-IB 7/3/14 as established by deep mate-pair sequencing on the MiSeq (Illumina) system. Journal of Biotechnology 203:19-21
Wijayawardene NN, Hyde KD, Rajeshkumar KC, Hawksworth DL, Madrid H, Kirk PM, Braun U, Singh RV, Crous PW, Kukwa M, Luecking R et al (2017) Notes for genera: Ascomycota. Fungal Diversity 86:1-594

Will-Wolf S, Jovan S, Amacher MC (2017) Lichen elemental content bioindicators for air quality in upper Midwest, USA: a model for large-scale monitoring. Ecological Indicators 78:253-263

Wingfield BD, Berger DK, Steenkamp ET, Lim HJ, Duong TA, Bluhm BH, De Beer ZW, De Vos L, Fourie G, Naidoo K, Olivier N (2017) IMA genome-F 8. Draft genome of Cercospora zeina, Fusarium pininemorale, Hawksworthiomyces lignivorus, Huntiella decipiens, and Ophiostoma ips. IMA Fungus 8:385-396

Wingfield BD, Bills GF, Dong Y, Huang W, Nel WJ, Swalarsk-Parry BS, Vaghefi N, Wilken PM, An Z, De Beer ZW, De Vos L (2018a) IMA genome-F 9. Draft genome sequence of Annulohypoxylon stygium, Aspergillus mulundensis, Berkeleyomyces basicola (syn. Thielaviopsis basicola), Ceratocystis smalleyi, two Cercospora beticola strains, Coleophoma cylindrospora, Fusarium fracticaudum. Phialophora cf. hyalina, and Morchella septimelata. IMA Fungus 9:199-221

Wingfield BD, Fourie A, Simpson MC, Bushula-Njah VS, Aylward J, Barnes I, Coetzee MPA, Dreyer LL, Duong TA, Geiser DM, Roets F, Steenkamp ET et al (2019) IMA genome-F 11. Draft genome sequences of Fusarium xylarioides, Teratosphaeria gauchensis and T. zuluensis and genome annotation for Ceratocystis fimbriata. IMA Fungus 10(13):1-10

Wingfield BD, Liu M, Nguyen HD, Lane FA, Morgan SW, De Vos L, Wilken PM Duong TA, Aylward J, Coetzee MPA (2018b) IMA Genome-F 10. Nine draft genome sequences of Claviceps purpurea s. lat., including C. arundinis, C. humidiphila, and C. cf. spartinae, pseudomolecules for the pitch canker pathogen Fusarium circinatum, draft genome of Davidsoniella eucalypti Grosmannia galeiformis, Quambalaria eucalypti, and Teratosphaeria destructans. IMA Fungus 9:401-418

Xu H, Luo X, Qian J, Pang X, Song J, Qian G, Chen J, Chen S (2012) FastUniq: a fast de novo duplicate removal tool for paired short reads. PLoS One 7 e52249

Zeng F, Wang C, Zhang G, Wei J, Bradley CA, Ming R (2017) Draft genome sequence of Cercospora sojina isolate S9, a fungus causing frog eye leaf spot (FLS) disease of soybean. Genomics Data 12:79-80

Zerbino DR, Birney E (2008) Velvet: algorithms for de novo short read assembly using de Bruijn graphs. Genome Research 18:821-829

Zimin AV, Marçais G, Puiu D, Roberts M, Salzberg SL, Yorke JA (2013) The MaSuRCA genome assembler. Bioinformatics 29:2669-2677

\section{Publisher's Note}

Springer Nature remains neutral with regard to jurisdictional claims in published maps and institutional affiliations.

Ready to submit your research? Choose BMC and benefit from:

- fast, convenient online submission

- thorough peer review by experienced researchers in your field

- rapid publication on acceptance

- support for research data, including large and complex data types

- gold Open Access which fosters wider collaboration and increased citations

- maximum visibility for your research: over $100 \mathrm{M}$ website views per year

At $\mathrm{BMC}$, research is always in progress.

Learn more biomedcentral.com/submissions 